ESRI

SURVEY AND

STATISTICAL

REPORT SERIES

NUMBER 91

MAY 2020
TECHNICAL DOCUMENTATION OF IBE MODEL,

VERSION 3

KELLY DE BRUIN AND AYKUT MERT YAKUT

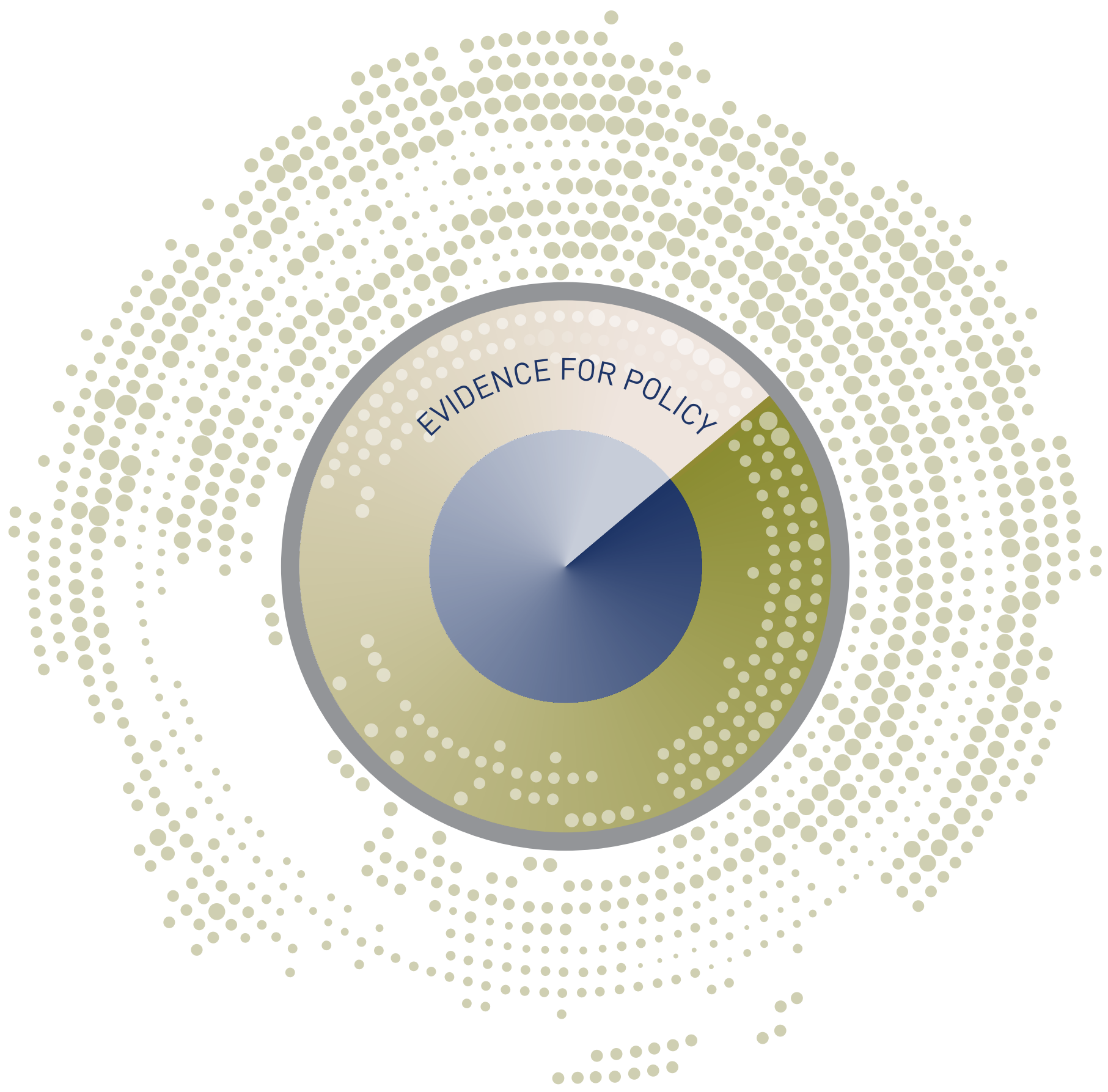




\section{Technical Documentation of I3E Model, Version 3}

Kelly de Bruin

Aykut Mert Yakut

May 2020

\section{ESRI SURVEY AND STATISTICAL REPORT SERIES NUMBER 91}

Available to download from www.esri.ie

() The Economic and Social Research Institute

Whitaker Square, Sir John Rogerson's Quay, Dublin 2

ISBN 978-0-7070-0527-0

DOI https://doi.org/10.26504/sustat91

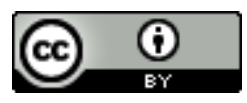

This Open Access work is licensed under a Creative Commons Attribution 4.0 International License (https:// creativecommons.org/licenses/by/4.0/), which permits unrestricted use, distribution, and reproduction in any medium, provided the original work is properly credited. 


\section{ABOUT THE ESRI}

The mission of the Economic and Social Research Institute is to advance evidence-based policymaking that supports economic sustainability and social progress in Ireland. ESRI researchers apply the highest standards of academic excellence to challenges facing policymakers, focusing on 12 areas of critical importance to 21 st Century Ireland.

The Institute was founded in 1960 by a group of senior civil servants led by Dr T. K. Whitaker, who identified the need for independent and in-depth research analysis to provide a robust evidence base for policymaking in Ireland.

Since then, the Institute has remained committed to independent research and its work is free of any expressed ideology or political position. The Institute publishes all research reaching the appropriate academic standard, irrespective of its findings or who funds the research.

The quality of its research output is guaranteed by a rigorous peer review process. ESRI researchers are experts in their fields and are committed to producing work that meets the highest academic standards and practices.

The work of the Institute is disseminated widely in books, journal articles and reports. ESRI publications are available to download, free of charge, from its website. Additionally, ESRI staff communicate research findings at regular conferences and seminars.

The ESRI is a company limited by guarantee, answerable to its members and governed by a Council, comprising 14 members who represent a cross-section of ESRI members from academia, civil services, state agencies, businesses and civil society. The Institute receives an annual grant-in-aid from the Department of Public Expenditure and Reform to support the scientific and public interest elements of the Institute's activities; the grant accounted for an average of 30 per cent of the Institute's income over the lifetime of the last Research Strategy. The remaining funding comes from research programmes supported by government departments and agencies, public bodies and competitive research programmes.

Further information is available at www.esri.ie 


\section{THE AUTHORS}

Kelly de Bruin and Aykut Mert Yakut are Research Officers at the Economic and Social Research Institute (ESRI).

\section{ACKNOWLEDGEMENTS}

The research carried out in this report was funded by the Department of Communications, Climate Action and Environment (DCCAE) and is part of an ongoing modelling project.

This report has been accepted for publication by the Institute, which does not itself take institutional policy positions. The report has been peer reviewed prior to publication. The authors are solely responsible for the content and the views expressed. 


\section{EXECUTIVE SUMMARY}

This paper provides a technical description of the Ireland Environment, Energy and Economy (I3E) model. The I3E model is an intertemporal computable general equilibrium model with multiple firms, one representative household group, multiple commodities, government, enterprises, and rest of the world accounts. It describes the Irish economy in sectoral detail. This model includes a detailed description of energy inputs and concomitant greenhouse gas emissions and has been developed with the purpose of investigating the economic and environmental impacts of climate policies for Ireland.

After each major development of the model, an updated version of this report is published. The current report belongs to the third version of the model. 


\section{Introduction}

Climate change and the associated challenges are at the forefront of current policy debates. For example, all countries have committed to the Paris Climate agreement (with the exception of the US). In line with this, climate policy is becoming increasingly important domestically, as Ireland is obliged to decrease its emissions under the EU Commission's Climate and Energy Package. Ireland is required to deliver a $20 \%$ reduction in non-ETS greenhouse gas emissions by 2020 relative to 2005 levels, increasing to $30 \%$ in 2030. Designing appropriate energy policies is imperative to ensure a smooth and least-cost transition to a low-carbon economy. Furthermore, a better understanding of the implications of such a transition is necessary, especially on a sectoral level, to identify those sectors most hit by climate policies. In this sense data-based economic models can be very useful to advise policy, giving insights into the realworld effects of different policy measures. Such models can investigate the economic costs and sectoral implications of reaching the EU goals and which specific climate policies (e.g., carbon tax, energy tax or quotas) can be implemented to reach these goals, accounting for the economic behaviour of producers and consumers.

To analyse the impacts of energy-related policies on the Irish economy, a model with sectoral details and various energy inputs and technologies is needed. With this objective in mind, the Ireland Environment, Energy and Economy model (I3E model) is developed. This model focusses on the relationship between the economy, energy inputs and environmental impacts in the form of greenhouse gas (GHG) emissions. The I3E model is an intertemporal computable general equilibrium (CGE) model with multiple firms, one representative household group (RHG), multiple commodities, government, enterprises, and rest of the world accounts.

This paper serves as a reference document concerning the technical details of the I3E model. In what follows, the model structure and equations will be presented

This document is structured as follows. In the next section, the sets, which represent the dimensions of the model, will be defined and clarified. Section 3 presents the equations dictating the behaviour of each agent in turn. Section 4 discusses the description of commodities in the model. In Section 5, the quantities are discussed and in Section 6, the prices. The energy part of the model is discussed in Section 7. Section 8 describes how economic growth is incorporated in I3E. Section 9 explains the savings-investment behaviour, and Section 10 gives the equilibrium conditions. The lists of activities and commodities can be found in Appendix A, the list of endogenous variables is presented in Appendix B, and finally, Appendix $C$ provides the list of exogenous variables and parameters. This document describes the second version of the I3E model. The main differences between the model versions can be found in Appendix E. 


\section{Sets}

The variables and parameters used within the model are defined over various sets, which are collections of different variables or parameters with common characteristics. Each set has a unique definition and contains elements that meet the defined criteria. The set logic is used to define equations over appropriate sets and allows us to exclude variables in the solution process. Each set and potential subsets are described in what follows.

\section{- Activities}

All activities are assigned to the set $a$. This is the broadest set for domestic production activities. Along with several dimensions, activities are assigned to several subsets as follows

\section{- Firm behaviour}

An Activity determines its level of investment, i.e. investment by destination, by dividend maximisation as explained in Section 3.2.1. This procedure is based on Tobin's $q$, which is defined as the market value of a firm's capital stock divided by the replacement cost of it; in other words, the marginal value of capital. If a firm's total investment expenditure is high, the market value and the replacement cost of its capital stock are of a similar magnitude and Tobin's $q$ approaches unity. If it is less than unity, the firm should not invest anymore. In the calibration process, some of the activities' Tobin's $q$ values are calibrated as less than unity, and these activities are considered non-dividend maximisers. See Section 3.2.1 for details.

Dividend maximising firms are assigned to the subset $d m_{a}$ and non-dividend maximising firms to $n d m_{a}$.

\section{- Production across commodities}

Activities are allowed to produce multiple products, and the quantity of production is determined by revenue maximisation as explained in Section 3.2.4. However, some activities either produce a single commodity or their production of a single commodity exceeds $95 \%$ of their total production. For these activities, total output is a Leontief aggregate of the commodity (if the activity is the unique producer) or commodities (if the production of a commodity exceeds the cut-off point). Otherwise, the activity's output is a constant elasticity of transformation (CET) aggregate of commodities that are produced by the activity in the base-year.

Activities for which the output is defined by CET function are assigned to the subset acet $_{a}$ and activities where the output is defined by a Leontief function are assigned to the subset aleo .

\section{- Energy demand}

The sets $a 1_{a}-a 4_{a}$ are created to distinguish activities concerning the composition of their energy demands by setting different elasticity of substitution values. The nested structures of production are explained in Section 3.2.2. The list of activities is provided in Appendix A. 


\section{- Commodities}

All commodities are assigned to the set $c$ which includes the following subsets:

\section{- Origin}

The set $c p_{c}$ contains commodities produced by domestic producers and sold in the domestic market. This set is defined over commodities for which the cells of activity rows and commodity columns on the Social Accounting Matrix (SAM) are positive. The set $c p n_{c}$ covers non-domestically produced commodities

\section{- Exports}

The set $c e_{c}$ is defined over export commodities, i.e. commodities for which the cells of commodity rows and the rest of the world columns on the SAM are positive. The set $c e n_{c}$ is the complementary set that covers non-exported commodities.

\section{- Imports}

The set $c m_{c}$ contains import commodities, i.e. commodities for which the cells of the rest of the world rows and commodity columns on the SAM are positive. The set $c m n_{c}$ covers non-imported commodities.

\section{- Homogeneity}

As explained in Section 3.2.4, activities are allowed to produce multiple products; however, there are a few commodities produced by a single activity, for instance, public administration. In this case, the commodity is homogeneous and assigned to the set $c h_{c}$. This set covers commodities for which the elasticity of substitution for the domestically produced commodity, $\sigma_{c, t}^{q x c s}$, is zero. The set $c h n_{c}$ is the complementary set that covers non-homogeneous commodities, i.e. commodities that are produced by at least two distinct activities and $\sigma_{c, t}^{q x c s}$ is positive.

\section{- Composite goods}

The model includes detailed nested structures of private composite consumption and production. The primary objective of creating such detailed nested structures is to reflect the compositions of households' and activities' demands for energy commodities as accurately as possible. In this sense, the way the nested structure is defined determines the substitutability between inputs to production and between goods for consumption. If goods are nested together, this represents higher substitutability between these goods compared to others. A Leontief relationship assumes no substitutability, whereas a constant elasticity of substitution (CES) relationship assumes a substitution possibility. The values of the elasticity of substitution parameter, $\sigma$, for different elasticity relations are chosen in order to reflect the low and high substitution possibilities among the commodities based on expert judgement.

\section{- Margins}

The set $m$ contains trade and transportation margins. 


\section{- Factors of production}

The set $f$ contains factors of production. In this version, it has two elements, Labour and Capital.

\section{- Capital}

One type of capital (physical capital) is defined in the model.

\section{- Labour}

The set $l$ has three elements: low skilled labour (LSL), medium skilled labour (MSL), and high skilled labour (HSL). The sectoral composition of employment by skill is retrieved from the Labour Force Survey (LFS). For each type of households $h h$, the composition of wage income by skill is retrieved from the Survey on Income and Living Conditions (SILC).

\section{- Households}

The set $h h$ is the broadest set for households. In this model version, there are ten RHGs (five groups in urban areas and five groups in rural areas). These RHGs have been generated based on disposable income by using the Household Budget Survey (HBS). The survey has also been used to derive the composition of consumption expenditures across commodities and the distribution of household disposable income across different income items.

\section{- Time}

The set $t$ comprises the horizon of the model and takes values between 2014 and 2054. In conventional CGE modelling, parameters do not have a time index. However, several parameters of the I3E model have a time index to generate a flexible model which allows dynamic simulations to be run. For instance, if the government wants to implement a policy change in 2020, the value(s) of relevant policy parameter(s) can be changed by 2020. If the model parameters do not have a time index, then the experiment would assume that the policy change starts in 2014. 


\section{Agents}

This section discusses the behaviour of each agent in the model in turn. The agents in the I3E model consist of households, activities, commodities, enterprises, and government,

\subsection{Households}

In this version, it is assumed that there is one RHG that solves the following intertemporal utility maximisation problem where the utility function is in the form of Constant Relative Risk Aversion (CRRA):

$$
\begin{gathered}
\max _{C C_{h h, t}} \sum_{t=1}^{\infty}\left(\frac{1+g r w_{t}}{1+\rho_{h h}}\right)^{t} \frac{\left(C C_{h h, t}\right)^{1-\theta_{h h}}}{1-\theta_{h h}} \\
\text { s.t } \\
S A V_{h h, t}+P C C_{h h, t} C C_{h h, t} \leq W I N C_{h h, t}+C I N C_{h h, t}+T R_{h h, t}+ \\
P E N_{h h, t}+\overline{N F I}_{h h, t} E R_{t}+R C I_{h h, t} \text { RCHH }_{t}+N M T T R_{h h, t}
\end{gathered}
$$

where $g r w_{t}$ is the economic growth rate in the period $t, \rho_{h h}$ is time preference rate, $\theta_{h h}$ is intertemporal elasticity of substitution, $W I N C_{h h, t}, C I N C_{h h, t}, T R_{h h, t}, P E N_{h h, t}$, and $\overline{N F I}_{h h, t}$ are net-of-tax wage income, net-of-tax capital income (distributed dividends of enterprises), transfers from the government, pension income from the government, net factor incomes from abroad (fixed in real terms), and non-meanstested transfer income from the government, respectively, $E R_{t}$ is exchange rate, $S A V_{h h, t}$ is savings, $C C_{h h, t}$ is household-specific composite consumption and $P C C_{h h, t}$ is its price. The term $R C I_{h h, t}$ is the carbon tax recycling income from the government and $\mathrm{RCHH}_{t}$ is a parameter (which is equal to zero in the calibration process) that allows for running an experiment in which the government recycles the carbon tax collection to households. The values of $R C I_{h h, t}$ and $N M T T R_{h h, t}$ are zero along all scenario analyses unless otherwise stated. The RHS of the budget constraint represents household disposable income, $I N C_{h h, t}$. The components of disposable income are as follows. ${ }^{1}$

$$
W_{I N C} C_{h h, t}=\left(\sum_{l} \gamma_{l, h h, t}^{\text {wage }} \sum_{a} W_{l, t} \overline{W F D I S T}_{a, l, t} L D_{a, l, t}\right)\left(1-w_{t a x} h h, t\right)
$$

where $\gamma_{l, h h, t}^{\text {wage }}$ is the share of household $h h$ in the total wage income of labour type $l$, and wtax $x_{h, t}$ is the wage income tax rate of household $h h$.

$$
\operatorname{CINC}_{h h, t}=\gamma_{h h, t}^{\operatorname{cinc}} \operatorname{DISDIV}{ }_{t}
$$

where $\gamma_{h h, t}^{\text {cinc }}$ is the share of household $h h$ in the total dividend (capital / asset) income.

1 For the sake of space saving, explanations of variables and parameters will be given in the relevant subsections. You can see Section 3.2.1 and also Appendix B. 
In this set-up, household savings are determined endogenously by

$$
S A V_{h h, t}=I N C_{h h, t}-P C C_{h h, t} C C_{h h, t}
$$

Household $h$ chooses the level of composite consumption to maximise the present discounted value of intertemporal utility. The first-order condition (FOC) of this problem, eq. (5), is the well-known consumption Euler equation and solves for the sequence of composite consumption where $r_{t}$ is interest rate.

$$
\frac{C C_{h h, t+1}}{C C_{h h, t}}=\left[\begin{array}{ll}
\left(1+g r w_{t}\right) \frac{1+r_{t+1}}{1+\rho_{h h}} & \frac{P C C_{h h, t}}{P C C_{h h, t+1}}
\end{array}\right]^{\frac{1}{\theta_{h h}}}
$$

In the second stage, household $h h$ disaggregates her composite consumption across commodities by maximising her intratemporal utility. The nested structure of household composite consumption is depicted by Figure 1.

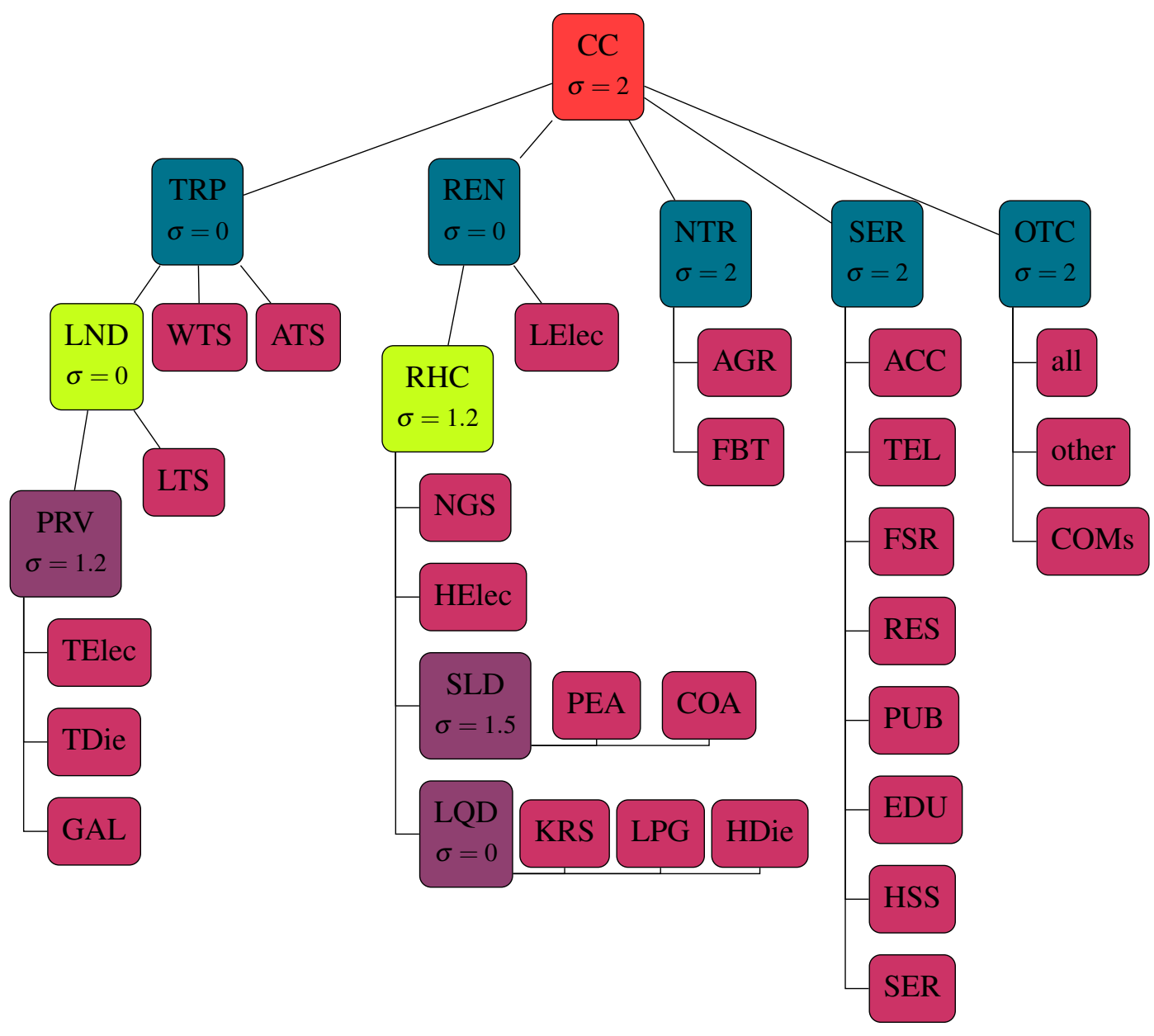

Figure 1: Nested Structure of Consumption 
Several composite commodities are included in the consumption nest; these are either constant elasticity of substitution (CES) or Leontief aggregates of directly observed commodities and/or other composite commodities. For the CES aggregates of the composite commodities, the values of elasticity of substitution parameters, $\sigma$ in Figure 1, are chosen in a range of 1.2 and 2 in order to reflect the different substitution possibilities across different commodities that constitute the composite commodity.

Household composite consumption, $C C$, is assumed to be a CES aggregate of composite commodities of Transportation (TRP), Residential Energy (REN), Nourishment (NTR), Services (SER), and other commodities $(O T C)$. As described above, this reflects that different services goods are easier to substitute with each other than, for example substituting services goods with nourishment goods. The logic here is that consumers are more likely to substitute food products with, e.g., agricultural products if prices of food products increase than to increase their consumption of services as food prices increase.

The composite commodity TRP is a Leontief aggregate of land, air, and water transportation commodities where land transportation $(L N D)$ is also a Leontief aggregate of public and private transportation commodities. The choice of a Leontief relationship here is warranted by the low level of substitutability between transport types; a consumer will not substitute their daily car commute with air or water transport due to increases in petrol prices. It should be noted that the original land transportation commodity (LTS with NACE Code 49) covers the public transportation demand of households. In I3E, we assign a share of household demand energy commodities including gasoline, diesel, and electricity for private transportation purposes. We refer to private transportation energy use as the composite commodity $L N D$, which is assumed to be a Leontief aggregate of that energy commodities. ${ }^{2}$ The REN is disaggregated into lighting electricity and residential heating which is further disaggregated into natural gas supply, solid fuel, heating electricity, and liquid fuel. Moreover, solid (liquid) fuel is a CES (Leontief) aggregate of peat and coal (kerosene, liquid petroleum gas, and diesel for heating purposes). The total electricity consumption of households, the commodity ELC, is known from the SAM, and it is disaggregated into electricity demand by transportation, lighting, and heating purposes by using the data provided by SEAI (2013, Table 19). Similarly, total private consumption of diesel is disaggregated into diesel demand for transportation and heating by using the energy balances. The composite commodity NTR is a CES aggregate of the commodities agriculture and food, beverage, and tobacco while the composite commodity SER is a CES aggregate of several service commodities. The composite commodity OTC is a CES aggregate of all remaining commodities that are demanded by households.

The compositions of electricity and diesel demands across their sub-components are assumed to be identical across households as there are no data available to make a further distinction. Moreover, the values of elasticity of substitution shown in Figure 1 are also assumed to be the same across households.

2 According to the energy balances, the private consumption of liquid petroleum gas is devoted both to private transportation and to residential heating. Since the former is a quite tiny portion of the total demand, it is assumed to be zero and liquid petroleum gas is assumed to be a part of the residential heating demand. 


\subsection{Activities}

\subsubsection{Investment by Destination}

The term "investment by destination" refers to investment expenditures of firms / sectors. In the model we distinguish between dividend maximisers and non-dividend maximisers; we discuss each in turn. In a fully intertemporal setting, the investment decision can be endogenised via a dividend maximisation problem where a firm maximises the present discounted value of its dividend stream, $D I V_{d m, t}$ (i.e. the present value of firm, $V_{d m, t}$ ) by choosing the level of physical investment, $P S I_{d m, t}$, and levels of factors of production (i.e. capital, $K_{d m, t}$, and composite labour, $C L D_{d m, t}$ ).

$$
\begin{gathered}
\max _{P S I_{d m, t}, K_{d m, t}, C L D_{d m, t}} V_{d m, t}=\sum_{t=1}^{\infty}\left(\frac{1+g r w_{t}}{1+r_{t}}\right)^{t} D I V_{d m, t} \quad \text { s.t } \\
K_{d m, t+1}\left(1+g r w_{t}\right)=\left(1-\delta_{d m, t}\right) K_{d m, t}+P S I_{d m, t}
\end{gathered}
$$

where $\delta_{d m, t}$ is the depreciation rate. Activity-specific capital stock $\left(K_{d m, t}\right)$ evolves according to capital accumulation function, eq. (7). The Lagrange multiplier of this maximisation problem, $q_{d m, t}$, which is constrained by capital accumulation function is the well-known Tobin's $q^{3}$, i.e. the marginal value of capital:

$$
\begin{gathered}
D I V_{d m, t}=\left(1-\operatorname{corptax}_{t}\right) W K_{d m, t} K_{d m, t}-I N V_{d m, t} \\
I N V_{d m, t}=P P S I_{t} P S I_{d m, t}+P V A_{d m, t} A D J_{d m, t} \\
A D J_{d m, t}=\phi_{d m, t} \frac{P S I_{d m, t}^{2}}{K_{d m, t}}
\end{gathered}
$$

where $W K_{d m, t}$ is the price of capital and $P P S I_{t}$ is the price of the investment. The sectoral dividend is equal to net-of-corporate tax sectoral profit minus total investment expenditures, $I N V_{d m, t}$, which includes the cost of new investment equipment and the adjustment cost. Adjustment cost is an increasing and convex function of investment; for a given level of sectoral capital stock, the cost of installing new capital equipment will be greater. Adjustment cost, $A D J_{d m, t}$, is measured by the price of the value added, $P V A_{d m, t}$, because it is assumed that installation of new capital requires the resources of the firm, which leads to interruption of the production process and thus losses of output.

The FOCs of this dividend maximisation problem w.r.t. the levels of physical investment and capital stock, respectively, are as follows.

$$
q_{d m, t}=P P S I_{t}+2 P V A_{d m, t} \frac{A D J_{d m, t}}{P S I_{d m, t}}
$$

3 Tobin's $q$ is the ratio of the market value of existing capital to its replacement cost. See Hayashi (1982) for further discussion. 


$$
\begin{aligned}
q_{d m, t}\left(1+r_{t}\right)\left(1+g r w_{t}\right)= & q_{d m, t+1}\left(1-\delta_{d m, t}\right)+P V A_{d m, t+1} \frac{A D J_{d m, t+1}}{K_{d m, t+1}} \\
& +\left(1-\operatorname{corptax}_{t}\right) W K_{d m, t+1}
\end{aligned}
$$

For non-dividend maximisers, the investment (by destination) expenditure in period $t$ of an activity is a fixed fraction of its total profits in period $t$ as follows, where $\gamma_{n d m, t}^{\text {invdes }}$ is a fixed parameter.

$$
I N V_{n d m, t}=\gamma_{n d m, t}^{\text {invdes }} W K_{n d m, t} K_{n d m, t}
$$

The level of investment expenditures determines the level of physical investment demand of a firm $\left(P S I_{n d m, t}\right)$ which, in turn, determines the level of sectoral capital stock $\left(K_{n d m, t}\right)$.

$$
\begin{gathered}
I N V_{n d m, t}=\operatorname{PPSI}_{t} \operatorname{PSI}_{n d m, t} \\
K_{n d m, t+1}\left(1+g r w_{t}\right)=\left(1-\delta_{n d m, t}\right) K_{n d m, t}+P S I_{n d m, t}
\end{gathered}
$$

The depreciation rate of these firms is arbitrarily set to be equal to 0.05 .

For all firms, either in the subset of $d m$ or $n d m$, the real value added, $V A_{a, t}$, is a CES aggregate of sectoral capital stock and sectoral composite labour

$$
V A_{a, t}=\lambda_{a, t}^{v a}\left[\gamma_{a, t}^{c v a} K_{a, t}^{-\rho_{a, t}^{v a}}+\left(1-\gamma_{a, t}^{c v a}\right) C L D_{a, t}^{-\rho_{a, t}^{v a}}\right]^{-\frac{1}{\rho_{a, t} a}}
$$

where $C L D_{a, t}$ is composite labour demand, $\gamma_{a, t}^{c v a}$ is the share parameter of capital in real value added, $\lambda_{a, t}^{v a}$ is the shift parameter, and $\rho_{a, t}^{v a}$ is the exponent parameter and obeys $\sigma_{a, t}^{v a}=1 /\left(1+\rho_{a, t}^{v a}\right)$.

The value added is equal to the sum of the payments to the factors of production

$$
P V A_{a, t} V A_{a, t}=W K_{a, t} K_{a, t}+C W_{a, t} C L D_{a, t}
$$

where $C W_{a, t}$ is price of sectoral composite labour input.

As the sectoral capital stocks evolve by following the law of motion for capital (7 and 15), the FOC of the cost minimisation problem yields the optimal level of composite labour demand

$$
C L D_{a, t}=\left[\frac{P V A_{a, t} \gamma_{a, t}^{c v a}}{C W_{a, t}\left(\lambda_{a, t}^{v a}\right)^{\rho_{a, t}^{v a}}}\right]^{\sigma_{a, t}^{v a}} V A_{a, t}
$$

Since the model comprises there types of labours, it is assumed that an activity chooses a sectorspecific composite labour input which is a CES aggregate of different types of labour. Each activity solves a cost minimisation problem to find the optimal combination of types of labours that minimises the cost of labour.

$$
\min _{L D_{a, l, t}} C W_{a, t} C L D_{a, t}=\sum_{l} L D_{a, l, t} \widetilde{W}_{l, t} \overline{W F D I S T}_{a, l, t} \quad \text { s.t }
$$




$$
C L D_{a, t}=\left[\sum_{l} \gamma_{a, l, t}^{c l d}\left(B X_{t} L D_{a, l, t}\right)^{-\rho_{a, t}^{c l d}}\right]^{-\frac{1}{\rho_{a, t}^{c l d}}}
$$

where $L D_{a, l, t}$ is labour demand of the activity, $\widetilde{W}_{l, t}$ is the wage per effective labour, $\overline{W F D I S T}_{a, l, t}$ is the ratio of factor payments to labour $l$ from activity $a$ to the wage rate of labour $l, B X_{t}$ is the level of labour productivity, $\gamma_{a, l, t}^{c l d}$ is the share of labour type $l$ in composite labour input of activity $a$, and $\rho_{a, t}^{c l d}$ is an exponent parameter. We need the term $\overline{W F D I S T}_{a, l, t}$ since the wage rate is determined by equilibrium conditions in the labour market for each type of labour, i.e. the model solves for three wage rates. However, since productivity of each type of labour is different, payments to labour cannot be the same across sectors. The term captures the distance between average and sectoral payments to labour.

In the case of labour-augmented technological growth, activities choose the level of "efficient labour", i.e. the multiplication of the labour demand and the level of productivity. Given the technological change, the wage per effective labour, $\widetilde{W}_{l, t}$, is constant while the wage per labour, $W_{l, t}-$ the wage received by labour - grows at the rate of technological change. For the given level of labour supply, labour is paid more in every period due to increases in its productivity. Hence, the following relation holds.

$$
W_{l, t}=\widetilde{W}_{l, t} B X_{t}
$$

The optimal level of labour demand is determined by

$$
\overline{B X}_{t} L D_{a, l, t}=\left[\frac{C W_{a, t} \gamma_{a, l, t}^{c l d} \overline{B X}_{t}}{W_{l, t} \overline{W F D I S T}_{a, l, t}}\right]^{\sigma_{a, t}^{c l d}} C L D_{a, t}
$$

\subsubsection{Production}

The total value of production, the LHS of eq. (22), is equal to payments to factors of production, i.e. value-added, production taxes paid to the government, the total cost of intermediate inputs, and the cost of the Emissions Trading System (ETS).

$$
P X_{a, t} Q X_{a, t}=P V A_{a, t} V A_{a, t}+P R O D T A X S_{a, t}+P C I N_{a, t} \operatorname{CCIN}_{a, t}+\text { CETS }_{a, t}
$$

where $Q X_{a, t}$ is an activity's total production and $C C I N_{a}$ is composite intermediate input demand; $P X_{a, t}$ and $P C I N_{a, t}$ are their prices, respectively.

The production of activities in the model is represented by a nested structure as shown in Figure 2. To reflect the differences in energy demand compositions, activities are assigned to three distinct groups at two different layers of the nested production structure. The elasticity of substitution parameter, $\sigma$, takes the value of 0 for activities which have a quite strict composition of energy demand. On the other hand, its value is either 1.1 or 1.3 for activities whose composition of the energy demand is not dominated by a specific energy commodity. 


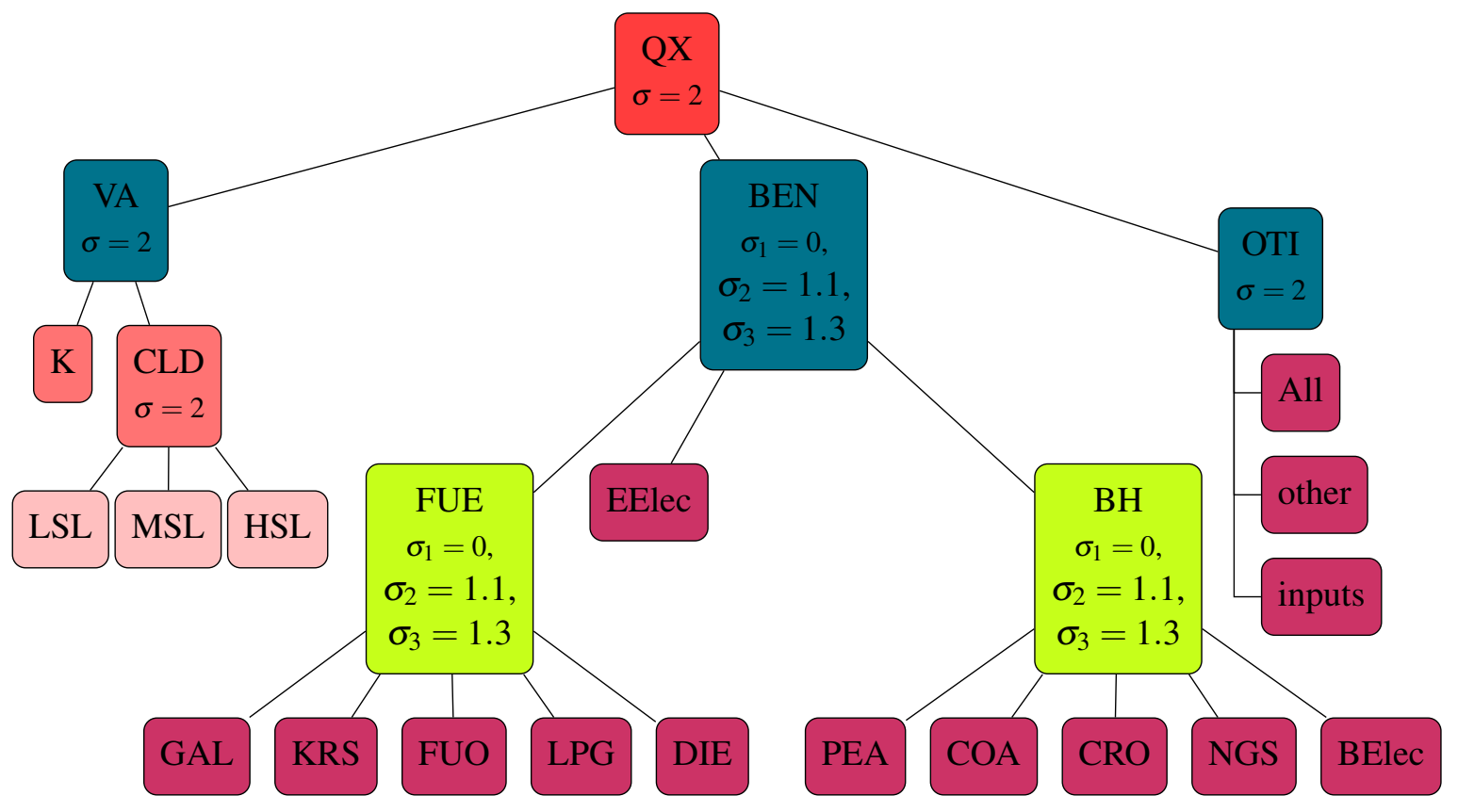

Figure 2: Nested Structure of Production, except Electricity Production

The activities are assumed to produce a composite product $Q X$, which is an aggregate of value added $(V A)$, business energy $(B E N)$, and other inputs $(O T I)$. The value added is a CES aggregate of factors of production, which are capital and composite labour, and the commodity OTI is an aggregate of all intermediate inputs except the energy commodities. The composite labour is a CES aggregate of three types of labour. For all activities, except the electricity production, the commodity $B E N$ is assumed to be an aggregate of energy electricity (EElec), fuel $(F U E)$ and business heating $(B H)$. The composite commodity $B H$ is an aggregate of liquid and solid fuels including coal, peat, crude oil, natural gas supply, and business electricity for heating purposes. On the other hand, the composite commodity $F U E$ is an aggregate of gasoline, kerosene, fuel oil, liquid petroleum gas, and diesel. The electricity demand of activities, except the electricity production, is disaggregated across demands for energy purposes and heating/combustion purposes. ${ }^{4}$ The nested structure of production of all activities except electricity production is depicted by Figure 2.

The electricity production activity has a unique production technology and energy demand composition. The activity's business energy, $B E N$, is assumed to be a CES aggregate of electricity, natural gas, and other energy (OTE) which is a CES aggregate of all remaining energy commodities, as shown in Figure 3. The value of $\sigma$ is 1.1 for the commodity of $B E N$ while it is 1.3 for the $O T E$ because the electricity production has more flexibility to substitute between liquid and solid fuels than natural gas and electricity's itself.

4 At this stage, the disaggregation is done by arbitrarily assuming that $40 \%(60 \%)$ of the total sectoral electricity is used for heating/combustion (energy). 


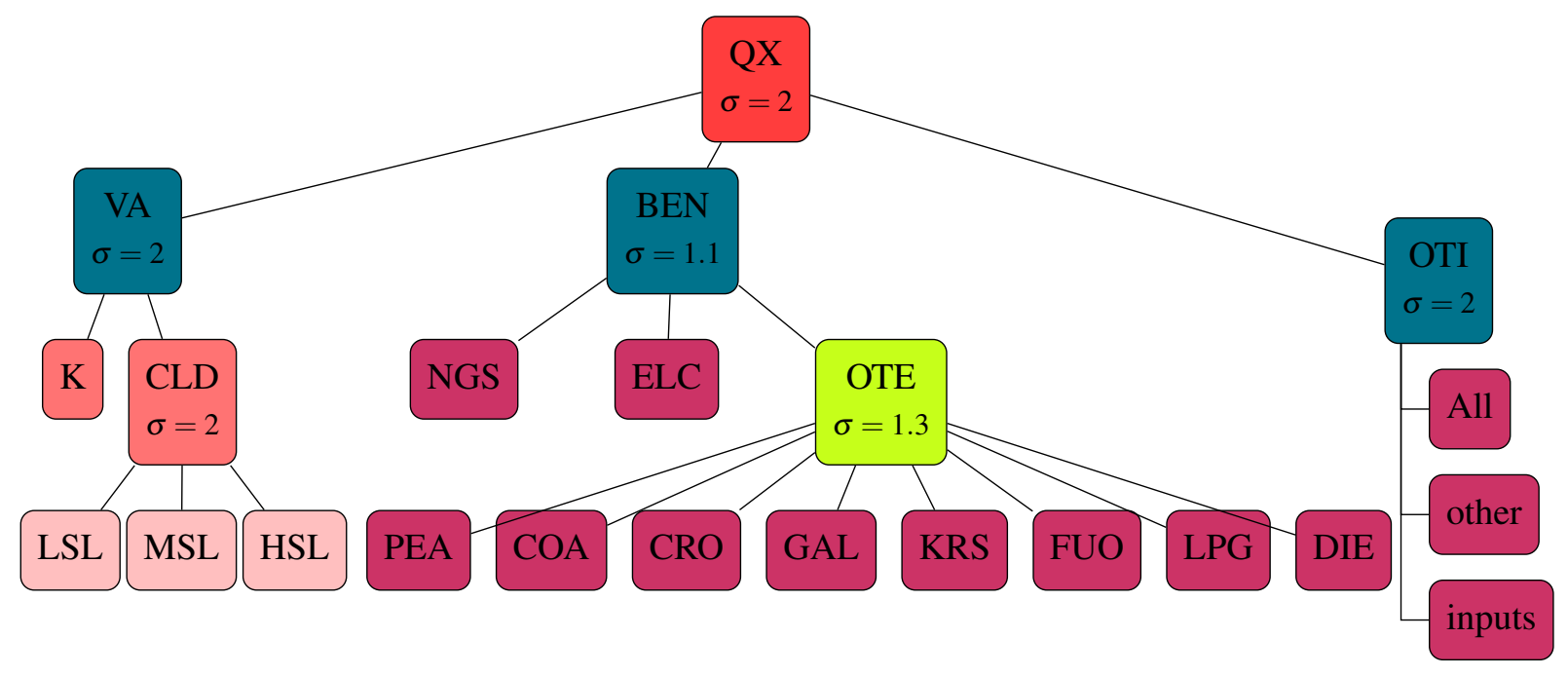

Figure 3: Nested Structure of Electricity Production

\subsubsection{Emissions Trading System}

The ETS is the European Union's (EU) key tool to reduce industrial emissions. In the current phase of the system, Phase-III that covers the period of 2013-2020, each installation (i.e. a production unit) receives an amount of free allowances (EU-ETS, 2018). If the installation's total emissions exceed its free allowances, the installation will need to purchase additional allowances ${ }^{5}$ at the ETS price determined in the EU-wide ETS market. If the installation emits less than its free allowances, it can sell its unused allowances to other installations at the EU-ETS price. In other words, the system generates a cost (revenue) for those installations which emit more (less) than their allowances. An installation may generate more revenue from the ETS system by reducing its emissions as it invests more on cleaner production technologies. Therefore, the last term on the RHS of eq. (22) is a cost (revenue) item if it is positive (negative).

The coverage of sectoral emissions by the ETS is $100 \%$ for the energy production sectors; energy production installations do not receive any free allowances and need to purchase allowances to cover all their emissions. Petroleum refining, mineral, and aviation sectors' emissions are also fully covered by the ETS, but installations operating in these industries receive some free allowances. On the contrary, land transportation (road or railway), agriculture, waste, and residential sectors are exempted from the ETS. For the other sectors, the ETS coverage varies based on the average size of production units regarding the combustion capacity, production capacity, etc. (EPA, 2018).

In the case of Ireland, the implementation of the EU-ETS legislation raises a complexity due to the mixed usage of the ETS and carbon taxation. ${ }^{6}$ In order to prevent double-taxation, the Irish government exempts the emissions covered by the ETS from the carbon tax. In other words, firms in Ireland which

5 In the EU-ETS terminology, the term "allowance" is also used to define emission permits.

6 Ireland is not the unique example of using two environmental policy tools. The other examples are Iceland, France, Portugal, Spain, Finland, Denmark, Sweden, Slovenia, Switzerland, Latvia, Estonia, Poland, Norway, the UK and Canada (except for NW Territories and Quebec.) For further details, see https ://carbonpricingdashboard. worldbank. org/map_data 
are subject to the EU-ETS legislation must directly internalise both the cost of ETS and the carbon tax exemptions in their cost minimisation problems. As an example, the optimal level of an intermediate input in the composite commodity of business heating $(B H)$ is

$$
I N T_{c, a, t}=\left[\frac{P C I N_{B H, a, t} \gamma_{c, a, t}^{b h}}{P Q D_{c, t}+\operatorname{ETSADJ}_{c, a, t}-C T X A D J_{c, a, t}}\right]^{\sigma_{a, t}^{b h}} \operatorname{CCIN}_{B H, a, t}
$$

where $I N T_{c, a, t}$ in intermediate input demand on commodity $c$ by activity $a, C C I N_{B H, a, t}$ is intermediate demand on the composite commodity $B H$ by activity $a$ and $P C I N_{B H, a, t}$ is its price, and $\gamma_{c, a, t}^{b h}$ and $\sigma_{a, t}^{b h}$ are share and exponent parameters of the CES function, respectively. ${ }^{7}$ The denominator in the parentheses is the total unit cost of a commodity $c$ for activity $a$ where $P Q D_{c, t}$ is purchaser price of commodity $c$, $E T S A D J_{c, a, t}$ is the ETS adjuster and $C T X A D J_{c, a, t}$ is the carbon tax exemption adjuster. The value of the ETS adjuster is equal to

$$
\operatorname{ETSADJ}_{c, a, t}=\overline{\operatorname{PETS}_{t}} \text { ETStoE }_{a, t}\left(1-\text { AtoT }_{a, t}\right) \operatorname{carcon}_{c}
$$

where $\overline{\operatorname{PETS}_{t}}$ is the EU-ETS price of a per tonne emission allowance, ETStoE $E_{a, t}$ is the ratio of ETS emissions to total emissions of activity $a, A t o T_{a, t}$ is the ratio of ETS allowance to ETS emissions of activity $a$, and carcon $_{c}$ is the carbon content of commodity $c$ which is calibrated by dividing total emission of commodity $c$ by its total consumption for the year of $2014 .^{8}$

The value of the carbon tax adjuster, on the other hand, is calculated as

$$
\operatorname{CTXADJ}_{c, a, t}=\overline{\operatorname{PCAR}_{t}} \text { ETStoE }_{a, t} \operatorname{carcon}_{c} \alpha_{c, t}\left(1+\operatorname{stax}_{c, t}\right)
$$

where $\overline{P C A R_{t}}$ is the unit carbon tax per tonne eq- $\mathrm{CO}_{2}, \alpha_{c, t}$ is a parameter in the carbon tax collection function that captures the carbon leakages in the economy, and $s t a x_{c, t}$ is the sales tax rate of commodity $c$.

The inclusion of the ETS and carbon tax exemption adjusters in eq. (23) makes the unit price of commodity $c$ a sector-specific perceived cost. The value of the parameter $E T S t o E_{a, t}$ is equal to zero if the activity $a$ is not subject to the EU-ETS. Therefore, the values of $E T S A D J_{c, a, t}$ and $C T X A D J_{c, a, t}$ are equal to zero and the cost of purchasing one more unit of commodity $c$ as an intermediate input, $I N T_{c, a, t}$, is equal to the purchaser price of the commodity, $P Q D_{c, t}$. As the purchaser price of commodity $c$ is inclusive of the carbon tax, activity $a$ bears the cost of the carbon tax. For instance, the agriculture sector is not covered by the ETS but the sector pays the carbon tax based on its demand for energy inputs with carbon content.

If $E T S t o E_{a, t}>0$, then activity $a$ needs to buy new allowances when its total ETS-covered emissions exceed the activity's free allowances. The term $\operatorname{ETSADJ}_{c, a, t}$ introduces this cost component into the

7 A fully fledged proof of the equations on the ETS system is available in Appendix D.

8 See Section 7 for details. 
optimality condition stemming from the cost minimisation problem. As the ETS price, the fraction of ETS emissions in total emissions and the carbon content of a commodity increase, the value of the ETS adjuster also increases which, in turn, increases the sector-specific perceived cost. The higher value of

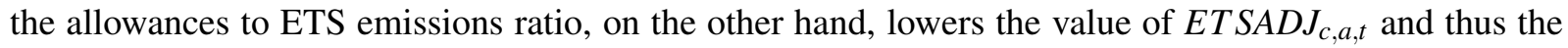
perceived cost. In other words, a higher level of $A t o T_{a, t}$ dampens the incentives for activity $a$ to lower its emissions covered by the ETS. Although activity $a$ is exempted from the carbon tax based on the ETS coverage of its total emissions, it pays the carbon tax-inclusive price of commodity $c, P Q D_{c, t}$, at the time of purchase. In the decision-making process, the activity should take into account the monetary value of the carbon tax exemptions, and the term $C T X A D J_{c, a, t}$ emerges for this purpose. The higher values of all variables on the RHS of eq. (25) increase the value of $C T X A D J_{c, a, t}$ and lower the sector-specific perceived cost.

The EU-ETS price is an exogenous variable since it is determined in the EU-wide allowance market, which is not explicitly incorporated in the I3E model. The ratio of ETS emissions to total emissions of an activity is a parameter (i.e. its value for each activity is calibrated by using the realised values of total and ETS emissions in 2014), and its value is assumed to be constant through time. However, the ratio of ETS allowance to ETS emissions of an activity is an endogenous variable. Total sectoral fuel combustion emissions are calculated as:

$$
\text { emis_act }_{a, t}=\sum_{c} \text { carcon }_{c} I N T_{c, a, t}
$$

The ETS emissions for the activity and the free allowances are given by:

$$
\begin{aligned}
& \text { emis_ETS }_{a, t}=\text { emis_act }_{a, t} \text { ETStoE } E_{a, t} \\
& \overline{\text { allowance }}_{a, t}=\text { AtoT }_{a, t} \text { emis_ETS } S_{a, t}
\end{aligned}
$$

where $\overline{\text { allowance }}_{a, t}$ is the free allowance, emis_ETS $S_{a, t}$ is the ETS emissions, and emis_act $t_{a, t}$ is the total emissions of activity $a$. In Phase III of the ETS, the freely allocated allowance of each installation and thus activity is known. In Phase IV that covers the period of 2021-2030, the free allowances of installations will be reduced by $1.74 \%$ (2.2\%) annually until 2030 for all sectors (the aviation). Applying these reductions, the sequence of free allowances for each activity is determined until 2030. As the structure of Phase V of the ETS has not been declared by the European Commission, the level of allowances beyond 2031 are assumed to be constant at their 2030 levels. Along the business-as-usual path of the model economy, as the free allowances decline, the value of $A t o T_{a, t}$ declines as well. Moreover, the positive trend in the EU-ETS price has also been applied in the BaU scenarios.

In the I3E model, ETS emissions are a fixed fraction of total emissions of an activity, hence for a given declining level of free ETS allowances, the allowances to ETS emissions ratio declines (eq. 27). For a given carbon content of the energy commodities and increasing level of the ETS price, the value of the ETS adjuster variable increases (eq. 24), which puts upward pressure on the unit cost of the intermediate input and thus reduces its demand. 
The process emissions of the aviation and mineral sectors constitute the second biggest portion of the free ETS allowances in Ireland. ${ }^{9}$ These emissions are calculated based on the level of sectoral output

$$
\text { emis_oETS }\left.S_{a, t}\right|_{\{a \in A T S, O N M\}}=\text { emis_oth }_{a, t} Q X_{a, t}
$$

where emis_OET $S_{a, t}$ is the other ETS emissions (i.e process emissions) and emis_ot $h_{a, t}$ is the share of the other ETS emissions in the sectoral output. For these emissions, the aforementioned two sectors also receive a free allowance, $\overline{\text { allowance_oth }}$, the sequence of which is also given until 2030. The level of these allowances beyond 2031 is assumed to be constant at their 2030 levels. To allow the ATS and ONM sectors to internalise the free allowance for their process emissions, another variable, namely allow_oth $h_{a, t}$, which is the ratio of other ETS allowances to sectoral output, is generated where

$$
\overline{\text { allowance_oth }}_{a, t}=\text { allow_oth }_{a, t} Q X_{a, t}
$$

The total cost of the ETS is given by

$$
\text { CETS }_{a, t}=\overline{\text { PETS }_{t}}\left(\text { emis_ETS }_{a, t}+\text { emis_OETS }_{a, t}-\overline{\text { allowance }}_{a, t}-\overline{\text { allowance_oth }}_{a, t}\right)
$$

\subsubsection{Multi-product Determination}

Each activity can produce multiple products, and the levels of output for each product are determined by a revenue maximisation problem. Gross production is a constant elasticity of transformation (CET) aggregate of the products produced by the activity if the activity is not the producer of a single commodity and the level of production of a single commodity does not exceed $95 \%$ of the total production of the activity.

$$
Q X_{a c e t, t}=\lambda_{\text {acet }, t}^{q x a c}\left[\sum_{c} \gamma_{a c e t, c, t}^{q x a c} Q X A C_{a c e t, c, t}^{\rho_{a c e c t}^{q x a}}\right]^{\frac{1}{\rho_{a c e c t}, t}}
$$

while total value of output has to be equal to the sum of values of each commodity produced:

$$
P X_{a c e t, t} Q X_{a c e t, t}=\sum_{c} P X A C_{a c e t, c, t} Q X A C_{a c e t, c, t}
$$

where $Q X A C_{a c e t, c, t}$ is the volume of production of commodity $c$ by activity acet and $P X A C_{a c e t, c, t}$ is its price, $\lambda_{\text {acet }, t}^{q x a c}$ is the shift parameter and $\gamma_{a c e t, c, t}^{q x a c}$ is the share parameter of commodity $c, \sigma_{\text {acet }, t}^{q x a c}$ is the elasticity of transformation and $\rho_{\text {acet }, t}^{q x a c}=1 / \sigma_{\text {acet }, t}^{q x a c}+1$ holds for $\sigma_{\text {acet }, t}^{q x a c} \in(0, \infty]$.

9 The aviation sector's process emissions come from the inconsistency between the verified ETS emissions of the sector and its fuel demand on the Energy Balance of Ireland. The inconsistency emerges from Ireland-based installations' fuel demand outside of Ireland. The energy demand appears in the corresponding country's energy balance sheet but the related emissions appear in the ETS account of the installation. The ATS sector's other ETS emissions eliminate this inconsistency. 
Each activity maximises (32) subject to (31) and the following FOC determines the level of production:

$$
Q X A C_{a c e t, c, t, \gamma_{\text {acet, }, t}^{q x a c}}^{q}=\left[\frac{P X A C_{a c e t, c, t}}{P X_{a c e t, t} \gamma_{a c e t, c, t}^{q x a c}\left(\lambda_{\text {acet }, t}^{q x a c}\right) \rho_{a c e t}^{q x a c}}\right]^{\sigma_{a c e t, t}^{q x a c}} Q X_{a c e t, t}
$$

As the price of commodity $c$ produced by activity acet increases, production increases. Note that eq. (33) is defined conditional on a positive production share of commodity $c$ in the total output of activity acet on the SAM. This implies that an activity is not able to produce commodities which are not produced in the base case.

For activities which produce a single commodity or the level of production of a single commodity exceeds $95 \%$ of total production of the activity, the level of production of each commodity is a fixed share of total output of the activity.

$$
\left.Q X A C_{a l e o, c, t}\right|_{\gamma_{\text {aleo }, c, t}^{\text {qxac }}}=\gamma_{\text {aleo }, c, t}^{q x a c} Q X_{a c e t, t}
$$

where $\gamma_{\text {aleo }, c, t}^{\text {qxac }}$ is the share parameter and obeys $\sum_{c} \gamma_{\text {aleo }, c, t}^{q x a c}=1$. The parameter is equal to 1 for a commodity $c$ if the activity is the unique producer.

\subsection{Labour Market}

Net migration flows to Ireland play an important role in the labour market structure in Ireland. In periods of economic expansion, for instance, as the wage rate increases and the unemployment rate decreases, the net migration into Ireland and thus the total labour supply in the economy increases. As the higher supply of labour lessens the upward pressure on the wage rate, firms are able to hire more employees without increasing their labour costs substantially. In periods of economic contraction, on the other hand, decreasing emigration lowers the total labour supply and prevents both larger declines in the wage rate and increases in the unemployment rate. In other words, net migration plays an important cushioning role in the Irish labour market.

In order to reflect the structure of the Irish labour market, the model incorporates involuntary unemployment and international migration. In the model, the total net migration, $N M I G_{t}$, is a function of the per-employee real net-of-tax wage income differential between Ireland and the rest of the world as follows. ${ }^{10}$

$$
N M I G_{t}=\zeta_{0, t}+\zeta_{1, t}\left(N W I N C_{t}-\overline{N F W I N C_{t}} E R_{t}\right)
$$

where $N W I N C_{t}$ and $\overline{N F W I N C_{t}}$ are the per-employee real net-of-tax wage income in Ireland and in the rest of the world, respectively. The latter variable is exogenous and fixed in the model, whereas the former

\footnotetext{
10 Since the I3E model is a single country model, there is no distinction between the source country of migrants. In the related literature, the net migration to Ireland is modelled as a function of the relative employment and wages (Kearney, 1998), the wage rate and unemployment rate differentials (Bergin et al., 2013), and the real after-tax earning differential (Bergin et al., 2017) between Ireland and the UK.
} 
one is calculated as follows.

$$
N W I N C_{t}=\frac{\sum_{h h} W I N C_{h h, t}}{C P I_{t} \sum_{a, l} L D_{a, l, t}}
$$

where $W I N C_{h h, t}$ (eq. 2) is the net-of-tax wage income of household $h h, L D_{a, l, t}$ (eq. 21 ) is the demand of activity $a$ for labour type $l$, and $C P I_{t}$ (eq. 91) is the consumer price index.

As there are three types of labour in the $\mathrm{I} 3 \mathrm{E}$ model, the disaggregation of the total net migration figure across the labour types is required. To this end, the LFS data is utilised to calibrate the share parameter of each type of labour in the total migration, $\mu_{l, t}$, and the net migration by skill type, $N M I G L_{l, t}$, is calculated.

$$
N M I G L_{l, t}=\mu_{l, t} N M I G_{t}
$$

The values of parameter $\mu_{l, t}$ are calibrated as $0.1108,0.3808$, and 0.5084 for the low-, medium-, and highskilled labour, respectively. In other words, half of the total net migration is constituted by high-skilled individuals.

The total labour supply of each type of labour is the sum of the net migration and the fraction of the Irish population that participates in the labour market.

$$
L S U P_{l, t}=\tau_{l, t} T P O P_{t}+N M I G L_{l, t}
$$

where $\tau_{l, t}$ is the labour force participation rate of labour type $l$ and $T P O P_{t}$ is the total Irish population. In this version of the model, the participation rate is assumed to be a parameter, i.e. the labour supply decision of the Irish population does not respond to changes in the labour market. ${ }^{11}$

The level of unemployment, $U N_{l, t}$, is the difference between the total labour supply and the total labour demand stemming from the cost-minimisation problem of firms as follows.

$$
L S U P_{l, t}=\sum_{a, l} L D_{a, l, t}+U N_{l, t}
$$

For a given level of unemployment for each type of labour, the unemployment rate is calculated as follows.

$$
U N R_{l, t}=\frac{U N_{l, t}}{L S U P_{l, t}}
$$

The equilibrium wage rate for each type of labour is determined by separate wage equations, eq. (41),

11 This structure differs from the labour market modelling choices in the aforementioned studies. The participation decision of the Irish population can be a function of the wage rate and/or the unemployment rate in the current version of the I3E model. In this case, the relationship between the labour market-related variables will be in a nearly-closed loop such that the impact of a policy change on the wage rate and the unemployment rate will be smooth. In the other studies, on the other hand, as econometric modelling and calibration strategies are applied, they can add other covariates such as a time trend. By doing so, they introduce another source of variation into the model. 
which relate the log of wage rate to the log of the unemployment rate.

$$
\log \left(\frac{W_{l, t}}{C P I_{t}}\right)=\omega_{0, l, t}+\omega_{1, l, t} \log \left(U N R_{l, t}\right)
$$

\subsection{Enterprises}

The model economy includes an "enterprises" account. The representative enterprise is assumed to be the owner of all firms. Such an assumption helps to simplify some details of the model and also avoids the need for detailed data which are not available. The enterprises account collects all gross sectoral profits and receives transfers from the government $\overline{G T R E N T}_{t}$ which is fixed in nominal terms, and pays corporate tax to the government, CORPTAXS . The remaining amount is either saved by the enterprise account, $E S A V_{t}$, or paid to households as dividend payments, $D I S D I V_{t}$.

$$
\operatorname{DISDIV}_{t}=\sum_{a} W K_{a, t} K_{a, t}+\overline{\operatorname{GTRENT}_{t}}-\mathrm{CORPTAX}_{t}-\mathrm{ESAV}_{t}
$$

It is assumed that enterprises savings is a fixed fraction, $\gamma_{t}^{\text {esav }}$, of net-of-tax profit receipts of the account:

$$
E S A V_{t}=\gamma_{t}^{e s a v}\left(\sum_{a} W K_{a, t} K_{a, t}-C O R P T A X S_{t}\right)
$$

\subsection{Government}

In this model economy, the government collects direct taxes on labour incomes (eq. 44), and on sectoral profits (i.e. corporate tax) (eq. 45), indirect taxes on sales of commodities (eq. 46), carbon tax on energy commodities (eq. 47), export tax on export of commodities (eq. 48), and production tax on production activities (eq. 49). The first half of the total cost of the ETS goes to the government whereas the second half goes to the EU Commission. The government allocates her total revenues to consumption and to transfers to households in terms of welfare transfers and pension. The real values of these transfers are fixed and their nominal values are indexed to the average wage rate. The total nominal values of these government transfers to households are distributed across households based on the fixed fractions.

Each type of labour pays a wage income tax at the rate $w_{t a x} x_{h, t}$ over their total income receipt from activities

$$
W_{T A X} S_{h h, t}=\operatorname{wtax}_{h h, t}\left(\sum_{l} \gamma_{l, h h, t}^{\text {wage }} \sum_{a} W_{l, t} \overline{\operatorname{WFDIST}}_{a, l, t} L D_{a, l, t}\right)
$$

Corporate tax is paid at a uniform rate across activities, corptax, by the enterprise account on total profits of activities

$$
\text { CORPTAXS } S_{t}=\operatorname{corptax}_{t} \sum_{a} W K_{a, t} K_{a, t}+\operatorname{TCTAX} S_{t} R C C T_{t}
$$

where TCTAXS $S_{t}$ is total carbon tax collection of the government and $R C C T_{t}$ is a parameter (which is equal 
to zero along the calibration process) that allows for running an experiment in which the government directs the carbon tax revenues to reduce the corporate tax rate. ${ }^{12}$

Sales tax on commodity $c$ is imposed on total domestic supply of the commodity, which is the sum of import and domestic production:

$$
\operatorname{SALTAX}_{c, t}=\operatorname{stax}_{c, t}\left(P M_{c, t} Q M_{c, t}+P D_{c, t} Q D_{c, t}\right)
$$

where $\operatorname{stax}_{c, t}$ is ad-valorem sales tax rate on commodity $c$. Carbon tax is collected on domestic consumption of energy commodities at fixed price of per-tonne equivalent of carbon, $\overline{P C A R}_{c, t}$, which is exogenously determined by the government,

$$
C T A X S_{c, t}=\alpha_{c, t} \overline{P C A R}_{c, t} \operatorname{carcon}_{c} Q S_{c, t}
$$

The parameter $\alpha_{c, t}$ shows the difference between the realised and the potential carbon tax collection of the government on commodity $c$. The parameter captures the value of carbon tax leakages in the Irish economy.

Although the domestic sale of electricity is exempted from the carbon tax, its export is subject to a carbon tax. Therefore, the total carbon tax collection of the government includes the export tax on electricity. Since the inclusion of carbon tax affects the domestic purchaser prices of commodities, the carbon tax payments on the consumption of electricity are set to zero. This amount is transferred to the export tax account on the SAM.

$$
E X P T A X S_{c, t}=\operatorname{exptax}_{c, t} P W E_{c, t} Q E_{c, t} E R_{t}
$$

where $\operatorname{exptax}_{c, t}$ is ad-valorem tax rate on the export of commodity $c$. The exptax is positive for only electricity and zero for the other commodities.

Activities pay production tax on the value of their total production

$$
\operatorname{PRODTAXS}_{a, t}=\operatorname{prodtax}_{a, t} P X_{a, t} Q X_{a, t}
$$

where prodtax $_{a, t}$ is ad-valorem tax rate on activity $a$.

Total revenue of the government is equal to summation of the six items above.

$$
\begin{gathered}
\text { GOVREV }_{t}=\sum_{a}\left(\text { PRODTAXS }_{a, t}+\text { CETS }_{a, t} 0.5\right)+\sum_{h h} \text { WTAXS }_{h h, t}+\text { CORPTAXS }_{t} \\
+\sum_{c}\left(\text { SALTAX }_{c, t}+\operatorname{CTAXS}_{c, t}+\operatorname{EXPTAXS~}_{c, t}\right)
\end{gathered}
$$

The total government consumption of commodities has an autonomous part which is fixed in nominal terms, $\overline{\text { GOVCONA }}$ and an induced part which is a positive function of the current period's nominal gross

\footnotetext{
12 For the other recycling schemes and their details, see Section 3.5.1.
} 
domestic product

$$
\text { GOVCON }_{t}=\overline{G O V C O N A_{t}}+\operatorname{mps~GDP}_{t}+\operatorname{TCTAXS}_{t} R C G C_{t}
$$

where the parameter mps stands for the government's marginal propensity to spend and $R C G C_{t}$ is a parameter (which is equal to zero along the calibration process) that allows for running an experiment in which the government directs the carbon tax collection to the government consumption. A simple ordinary least square (OLS) analysis shows that the value of $m p s$ is 0.05 when the first difference of the government consumption is regressed on the first difference of GDP. If the level of government consumption is regressed on the level of GDP, the parameter mps becomes 0.106 . To lower the sensitivity of the induced government expenditures, the first differences are used. The level of government consumption of each commodity is a simply fixed fraction, $\gamma_{c, t}^{g c}$, of its total consumption

$$
P Q D_{c, t} C G_{c, t}=\gamma_{c, t}^{g c} G O V C O N_{t}
$$

where $C G_{c, t}$ is the government consumption demand for commodity $c$.

The difference between total revenues and expenditures of the government is public savings:

$$
\begin{gathered}
G S A V_{t}=\text { GOVREV } V_{t}-\text { GOVCON }_{t}-\left(\overline{\text { GTRHH }_{t}}+\overline{\text { TOTPEN }_{t}}\right) W_{-} \text {mean }_{t}- \\
\overline{\text { GTRENT }_{t}}-\text { GFINT }_{t} \text { ER }_{t}-\text { TCTAXS }_{t} \text { RCHH }_{t}
\end{gathered}
$$

where $\overline{\text { TRRHH }_{t}}$ and $\overline{\text { TOTPEN }_{t}}$ are the real values of the total government welfare transfers and pension payments to households, respectively, and $W_{-}$mean $_{t}$ is the average wage rate. The real values of these transfers are assumed to be fixed but the government updates them based on the change in the average nominal wage. These transfers are distributed across households by fixed parameters,

$$
\begin{aligned}
T R_{h h, t} & =\gamma_{h h, t}^{g t r h h} \overline{G T R H H_{t}} W_{-} \text {mean }_{t} \\
\text { PEN }_{h h, t} & =\gamma_{h h, t}^{\text {penhh }} \overline{\text { TOTPEN }_{t}} W_{\text {mean }_{t}}
\end{aligned}
$$

$G F I N T_{t}$ is the interest payments of the government to the rest of the world over the outstanding foreign debt stock, $G F D S_{t}$, which grows by the level of government savings:

$$
\begin{gathered}
G F I N T_{t}=r_{t} G F D S_{t} \\
G F D S_{t+1}=G F D S_{t}-G S A V_{t} / E R_{t}
\end{gathered}
$$

\subsubsection{Carbon Tax Revenue Recycling Schemes}

In the context of environmental policies, achieving a double dividend (a decline in emissions and an economic efficiency gain through a reduction in distortionary taxes) and counteracting the regressive nature 
of environmental policies play an important role. In this respect, recycling of carbon / environmental tax collection to other agents in the economy rather than its usage by the government is considered the primary policy tool to achieve a double dividend and/or reduce inequality. In the design of recycling schemes, governments have several options such as transferring the funds to households directly (unconditionally) or reducing tax rates such as wage income tax rate, production tax rate of (selected) activities, corporate tax rate, and sales tax (VAT) rates. A government may choose not to recycle the tax collection and use it to increase government expenditures or to reduce debt stock. In order to simulate all those policy options, the I3E model includes a flexible recycling mechanism. This section is devoted to explaining how the system of equation is capable of evaluating all recycling options.

If the Irish government chooses not to recycle the carbon tax collection, the increased amount of $\operatorname{tax}$ collection is used to reduce the foreign debt stock. Since all policy switching parameters $\left(R C C T_{t}, R C G C_{t}\right.$, $\mathrm{RCHH}_{t}$ ) are equal to zero, the entire carbon tax collection remains in the total government revenue which increases the public savings via eq. (53).

If the government directs the total carbon tax collection to households in the form of unilateral transfers, this would directly affect the government savings and household disposable income via positive recycling income

$$
R C I_{h h, t}=\gamma_{h h, t}^{r c h} T C T A X S_{t} R C H H_{t}
$$

where $\gamma_{h h, t}^{r c h}$ is the share of household $h h$ in the total carbon recycling income and is assumed to be equal to the households' share in government transfers $\gamma_{h h, t}^{g t r h h}$. This experiment is run by switching the value of $R C H H_{t}$ from 0 to 1.

Similarly, if the government uses the total carbon tax collection to increase government consumption, the value of parameter $R C G C_{t}$ in eq. (51) is switched from 0 to 1 . In this case, the government expenditure increases by the total carbon tax collection and the government savings decrease.

In order to quantify the impacts of the other recycling schemes, the tax rates intended to be reduced must be endogenous variables rather than parameters. To hold the numbers of the equation and endogenous variables equal, a new set of equations must be defined for tax rates.

In the corporate tax rate reduction option, a new equation is not needed since the corporate tax rate has no activity or commodity dimension, i.e. it is a uniform rate across activities. Therefore, an experiment can be designed such that the value of parameter $R C C T_{t}$ is switched from 0 to 1 in eq. (45) and the value of corporate tax collection is fixed to its baseline level. Since one variable is fixed, without having a new

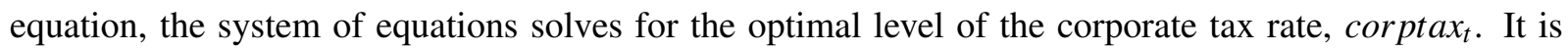
evident from eq. (45) that for the fixed CORPTAXS $S_{t}, R C C T_{t}=1$ increases the RHS of the equation and forces corptax to decline.

The following two equations govern the process of reducing the income tax rate by using the carbon tax collections

$$
T W T A X S_{t}=\sum_{h} W T A X S_{h h, t}+\operatorname{TCTAX} S_{t} R C W T_{t}
$$




$$
\operatorname{wtax}_{h h, t}=\operatorname{wtax}_{h h, 0} W T A D J_{t}-W T A D J P_{t} W T 01_{h h, t}
$$

where $T W T A X S_{t}$ is the total wage tax collection, $R C W T_{t}$ is a policy switching parameter (which is calibrated to 0), $w t a x_{h h, 0}$ is the calibrated wage income tax rate of household $h h, W T A D J_{t}$ and $W T A D J_{-} P_{t}$ are full and partial tax rate adjuster variables which are set to 1 and 0 , respectively, and $W T 01_{h h, t}$ is a binary parameter for each household. Without a policy change, $R C W T_{t}$ and $W T A D J P_{t}$ are equal to 0 , $W T A D J_{t}$ is equal to $1, W T 01_{h h, t}$ is 0 for all households, and eq. (59) solves for the wage income tax rate that is exactly equal to its calibrated value.

In an experiment of wage income tax rate reduction, the value of TWTAXS level and the value of parameter $R C W T_{t}$ is switched from 0 to 1 . In this case, for the fixed LHS of eq. (58), the RHS increases and forces $W T A X S_{h h, t}$ to decline via reduction in wtax $x_{h h, t}$.

As one variable is fixed, $T W T A X S_{t}$, another variable must freely adjust to obtain a consistent solution. In this policy setting, the government has two options; reducing all wage income tax rate equiproportionally or excluding some of households in the wage income tax rate reduction. Alterations in the wage income tax rates are driven by $W T A D J_{t}$ and $W T A D J_{-} P_{t}$. In the first option, the variable $W T A D J_{t}$ freely adjusts (while $W T A D J_{-} P_{t}$ is 0 ) and lowers all wage income tax rates by the same percentage change. If the government directs the carbon tax collections to reduce the wage income tax rates of only rural households, the binary variable $W T 01_{h h, t}$ is set to 1 for rural households while its value for urban households is still equal to 0 . Then, $W T A D J_{-} P_{t}$ adjusts (while $W T A D J_{t}$ is 1 ) to reach a solution by lowering the wage income tax rates of rural households by the same absolute value.

Another policy option of the government is using the carbon tax collection to reduce the production tax rates of activities, $\operatorname{prodtax}_{a, t}$. A similar structure to that of the wage income tax reduction option is built as follows

$$
\begin{aligned}
& \text { TPRODTAXS } \\
& t=\sum_{a} P R O D T A X S_{a, t}+C T A X S_{t} R C P T_{t} \\
& \operatorname{prodtax}_{a, t}=\operatorname{prodtax}_{a, 0} P T A D J_{t}-P T A D P_{-} P_{t} P T 01_{a, t}
\end{aligned}
$$

where TPRODTAXS $S_{t}$ is the total production tax collection, $R C P T_{t}$ is a policy switching parameter (which is calibrated to 0 ), $\operatorname{prodtax}_{a, 0}$ is the calibrated production tax rate of activity $a, P T A D J_{t}$ and PTADJ $P_{t}$ are full and partial tax rate adjuster variables which are set to 1 and 0 , respectively, and $P T 01_{a, t}$ is a binary parameter for each activity. Without a policy change, $R C P T_{t}$ and $P T A D J P_{t}$ are equal to $0, P T A D J_{t}$ is equal to $1, P T 01_{l, t}$ is 0 for all activities, and eq. (61) solves for the production tax rate that is exactly equal to its calibrated value.

In an experiment of production tax rate reduction, the value of TPRODTAXS $S_{t}$ is fixed to its baseline level and the value of parameter $R C P T_{t}$ is switched from 0 to 1 . In this case, for the fixed LHS of eq. (60), the RHS increases and forces PRODTAXS $S_{a, t}$ to decline via reduction in prodtax $x_{a, t}$.

In this policy option, the government may reduce all production tax rates equiproportionally (set 
$P T A D J P_{t}$ to 0 , allow $P T A D J_{t}$ to freely adjust, sectoral tax rates decline by the same percentage change) or may exempt some of the activities from the policy (set $P T A D J_{t}$ to 1 , allow $P T A D J P_{t}$ to freely adjust, the tax rates decline by the same absolute value). The latter option allows the government to use the carbon / environmental tax collection to reduce the cost of production of cleaner energy producers rather than treating all activities equally.

The last policy option is reducing the sales (value-added) tax rates. The following equations govern this process

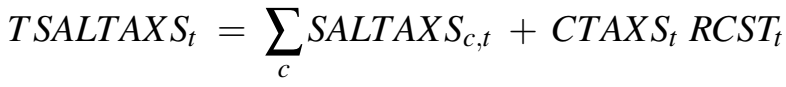

$$
\begin{aligned}
& \operatorname{stax}_{c, t}=\operatorname{stax}_{c, 0} S T A D J_{t}-S T A D J P_{t} S T 01_{c, t}
\end{aligned}
$$

where TSALTAXS $S_{t}$ is the total sales tax collection, $R C S T_{t}$ is a policy switching parameter (which is calibrated to 0), $\operatorname{stax}_{c, 0}$ is the calibrated sales tax rate of commodity $c, S T A D J_{t}$ and $S T A D J_{-} P_{t}$ are full and partial tax rate adjuster variables which are set to 1 and 0 , respectively, and $S T 01_{c, t}$ is a binary parameter for each commodity. Without a policy change, $R C S T_{t}$ and $S T A D J_{-} P_{t}$ are equal to $0, S T A D J_{t}$ is equal to $1, S T 01_{c, t}$ is 0 for all commodities, and eq. (63) solves for the sales tax rate that is exactly equal to its calibrated value.

In an experiment of sales tax rate reduction, the value of $T S A L T A X S_{t}$ is fixed to its baseline level and the value of parameter $R C S T_{t}$ is switched from 0 to 1 . In this case, for the fixed LHS of eq. (62), the RHS increases and forces $\operatorname{SALTAX} S_{c, t}$ to decline via a reduction in $\operatorname{stax}_{c, t}$.

In this policy option, the government may reduce all sales tax rates equiproportionally (set $S T A D J P_{t}$ to 0 , allow $S T A D J_{t}$ to freely adjust, the tax rates decline by the same percentage change) or may set some of the commodities exempted from the policy (set $S T A D J_{t}$ to 1, allow $S T A D J_{P_{t}}$ to freely adjust, the commodity tax rates decline by the same absolute value). The latter option allows the government to use the carbon / environmental tax collection to reduce the sales tax rates of a selected set of commodities. Considering equiproportional declines in sales tax rates is not a meaningful policy option since it also covers the carbon commodities; the government would be increasing the carbon tax to lower the sales tax rates of the energy commodities. Hence excluding energy commodities from the tax reduction would make sense. Moreover, the government has room to extend the set of excluded commodities in the policy design, e.g. alcoholic beverages and tobacco products may also be excluded.

\section{Commodities}

Commodity supply consists of the production from domestic producers and imports. Commodity demand consists of the demand for intermediate usage, household (private) demand, government demand, investment demand, trade and transportation margins demand, and export demand.

Data concerning supply and demand of commodities are retrieved from the Supply and Use Tables (SUTs), where the commodity production per activity and the various demands are given. The SUTs, 
however, only provide the value of exports by commodities but not which activities' outputs are exported. For this reason, we define a commodity, namely $Q X C_{c, t}$, that is a CES composite of domestically produced commodities. Its volume and value are as follows:

$$
\begin{gathered}
\left.Q X C_{c, t}\right|_{\left\{c p_{c} \text { and } c h n_{c}\right\}}=\lambda_{c, t}^{q x c s}\left[\sum_{a} \gamma_{a, c, t}^{q x c s} Q X A C_{a, c, t}^{-\rho_{c, t}^{q x c s}}\right]^{\frac{-1}{\rho_{c, t} x s}} \\
P X C_{c, t} Q X C_{c, t}=\sum_{a} P X A C_{a, c, t} Q X A C_{a, c, t}
\end{gathered}
$$

where $P X C_{c, t}$ is price of composite commodity $Q X C_{c, t}$. Equation (64) is defined over the set $c p_{c}$ to control for positive values of $Q X A C_{a, c, t}$ and over the set $c h n_{c}$ to control for non-homogeneous commodities. For commodities that are not produced domestically, $\left.Q X C_{c, t}\right|_{c p n_{c}}=0$ holds while for homogeneous commodities, the volume of the composite commodity $Q X C_{c, t}$ is equal to production of activity $a$

$$
\left.Q X C_{c, t}\right|_{\left\{c h_{c}\right\}}=\sum_{a} Q X A C_{a, c, t}
$$

The commodity $Q X C_{c, t}$ is either sold in the domestic market or exported. From the demand side, demand is assumed to be a CET aggregate of domestic sales and exports. The volumes of these components are determined by FOCs of a profit maximisation problem in which eq. (67) is maximised subject to eq. (68)

$$
\begin{gathered}
\left.Q X C_{c, t} P X C_{c, t}\right|_{\left\{c p_{c}\right\}}=P D_{c, t} Q D_{c, t}+P E_{c, t} Q E_{c, t} \\
\left.Q X C_{c, t}\right|_{\left\{c e_{c}\right\}}=\lambda_{c, t}^{q x c d}\left[\gamma_{c, t}^{q x c d} Q D_{c, t}^{\rho_{c, t}^{q x c d}}+\left(1-\gamma_{c, t}^{q x c d}\right) Q E_{c, t}^{\rho_{c, t}^{q x c d}}\right]^{\frac{1}{\rho_{c, t}^{q x c d}}}
\end{gathered}
$$

where $Q D_{c, t}$ is volume of sales in the domestic market and $P D_{c, t}$ is its producer price, $Q E_{c, t}$ is volume of exports and $P E_{c, t}$ is its price in domestic currency. The price of composite commodity $\left(P X C_{c, t}\right)$ is defined over the set of domestically produced commodities because supply of the composite commodity $\left(Q X C_{c, t}\right)$ comes from the domestic producers. If it is not produced by domestic producers, its price is equal to zero, $\left.P X C_{c, t}\right|_{\left\{c p n_{c}\right\}}=0$. The FOC of this problem yields

$$
\left.Q E_{c, t}\right|_{\left\{c e_{c}\right\}}=\left[\frac{P E_{c, t} \gamma_{c, t}^{q x c d}}{P D_{c, t}\left(1-\gamma_{c, t}^{q x c d}\right)}\right]^{\sigma_{c, t}^{q x c d}} Q D_{c}
$$

The volume of export is a positive function of its price denominated in domestic currency. Equations (68) and (69) are defined over the set of export commodities only. This is because it is highly improbable that commodities are imported solely for the purpose of exporting them. For commodities that are not in 
the subset of export commodities, the volume of their domestic demands are equal to their supply

$$
\left.Q D_{c, t}\right|_{\left\{c e n_{c}\right\}}=Q X C_{c, t}
$$

By following the convention in the literature, it is assumed that domestically produced commodities that are sold in the domestic market $\left(Q D_{c, t}\right)$ and imports $\left(Q M_{c, t}\right)$ are imperfect substitutes of each other. These two generate a composite commodity $Q S_{c, t}$ via a CES function.

$$
\left.Q S_{c, t}\right|_{\left\{c p_{c} \text { and } c m_{c}\right\}}=\lambda_{c, t}^{a r m}\left[\gamma_{c, t}^{a r m} Q D_{c, t}^{-\rho_{c, t}^{a r m}}+\left(1-\gamma_{c, t}^{a r m}\right) Q E_{c, t}^{-\rho_{c, t}^{a r m}}\right]^{\frac{-1}{\rho_{c, t}}}
$$

The FOC of the following cost minimisation problem yields the optimal volume of import demand, $Q M_{c, t}$.

$$
\begin{gathered}
P Q S_{c, t} Q S_{c, t}=P D_{c, t} Q D_{c, t}+P M_{c, t} Q M_{c, t} \\
\left.Q M_{c, t}\right|_{\left\{c p_{c} \text { and } c m_{c}\right\}}=\left[\frac{P D_{c, t}\left(1-\gamma_{c, t}^{a r m}\right)}{P M_{c, t} \gamma_{c, t}^{a r m}}\right]^{\sigma_{c, t}^{a r m}} Q D_{c, t}
\end{gathered}
$$

where $P Q S_{c, t}$ is purchaser price of composite commodity $c . P M_{c, t}$ is import price of commodity $Q M_{c, t}$ including tariffs and denominated in domestic currency.

Equation (71) is defined over both sets of domestically produced $\left(c p_{c}\right)$ and imported $\left(c m_{c}\right)$ commodities. For commodities either not domestically produced but imported ( $P D_{c, t}$ is undefined) or domestically produced but not imported $\left(P M_{c, t}\right.$ is undefined), total domestic demand is linear summation of imports and domestic sales

$$
\left.Q S_{c, t}\right|_{\left\{c p n_{c} \text { and } c m_{c}\right\}} \text { OR }\left\{c p_{c} \text { and } c m n_{c}\right\}=Q M_{c, t}+Q D_{c, t}
$$

\subsection{Margins}

Trade and transportation services are necessary to deliver commodities from factories and docks to markets. Producer prices, $P D_{c, t}$, do not comprise the cost of these margins since these are not part of the production process. These costs are paid by final users of commodities and are included in purchaser prices, $P Q S_{c, t}$. Since a commodity is produced by several activities and the cost of trade and transportation margins is paid by consumers, margins are demanded by commodities. Each commodity demands margin $m$ as a fixed fraction, marg_ $_{m, c}$, of its total composite supply, and the total volume of these demands is equal to the total supply of margins, $Q S T M_{m, t}$ :

$$
Q S T M_{m, t}=\sum_{c} \operatorname{marg}_{-} d_{m, c} Q S_{c, t}
$$

where the set $m$ stands for margins and consists of a single element as we have information only on the total of trade and transportation margins in the national accounts. Then, margin demand in terms of commodities is a fixed fraction of this supply, i.e via Leontief technology, and its price is simply equal to 
the weighted average of the commodities' purchaser prices

$$
\begin{gathered}
\operatorname{QDTM}_{c, t}=\sum_{m} \operatorname{marg}_{s_{c, m}} \operatorname{QSTM}_{m, t} \\
\operatorname{PTM}_{m, t}=\sum_{c}{\operatorname{marg} s_{c, m} P Q D_{c, t}}^{\text {Par }}
\end{gathered}
$$

where $Q D T M_{c, t}$ is margin demand of commodity $c, \operatorname{marg}_{s, m}$ is the share parameter of commodity $c$ in total margin supply of $m$ and $P T M_{m, t}$ is margin price.

\section{Quantities}

The total intermediate demand of commodity $c$ is simply equal to the summation of activities' intermediate demands, eq. (78), and total private, i.e. household, demand for commodity $c$ is the summation of all households' demands, eq. (79).

$$
\begin{gathered}
\operatorname{QINT}_{c, t}=\sum_{a} I N T_{c, a, t} \\
\operatorname{TOTPRCON}{ }_{c, t}=\sum_{h h} C D_{c, h h, t} \\
G D P_{t}=\sum_{a}\left(\operatorname{PVA}_{a, t} V A_{a, t}+\operatorname{PRODTAX} S_{a, t}\right)+ \\
\sum_{c}\left(\operatorname{SALTAX}_{c, t}+\operatorname{CTAXS}_{c, t}+\operatorname{EXPTAXS}_{c, t}\right)
\end{gathered}
$$

The total value of the gross domestic product, $G D P_{t}$, by the value-added approach is equal to the summation of the value added in each sector and indirect taxes on production activities, sales of commodities and international trade.

\section{Prices}

Here we discuss the various prices used in the model. The export price of commodity $c$ denominated in domestic currency received by the exporter, $P E_{c, t}$, is equal the product of world price of commodity $c$, $P W E_{c, t}$, exchange rate, $E R_{t}$ and export tax rate, $\operatorname{exptax}_{c}$.

$$
\left.P E_{c, t}\right|_{\left\{c e_{c}\right\}}=P W E_{c, t}\left(1-\operatorname{exptax}_{c, t}\right) E R_{t}
$$

If the value of $\operatorname{exptax}_{c, t}$ is positive (negative), the domestic price is lower (higher) than the international price, so it represents a tax (subsidy). World prices are conventionally defined as fixed parameters without a time subscript. However, due to the quite volatile pattern of international energy prices, the time subscript is added to allow us to give the time sequence of the prices. 
The import price of commodity $c$ denominated in domestic currency, $P M_{c, t}$, is equal the product of the world price of commodity $c, P W M_{c, t}$, exchange rate, $E R_{t}$, and tariff rate, tarif $f_{c, t}$.

$$
\left.P M_{c, t}\right|_{\left\{c m_{c}\right\}}=P W M_{c, t}\left(1+\operatorname{tariff} f_{c, t}\right) E R_{t}
$$

Since Ireland is a member of the Customs Union, the trade flows between the EU member states are exempted from import tariffs. On the other hand, the main trade partners of Ireland are the $\mathrm{UK}^{13}$ (onethird and one-sixth of the total merchandise imports and exports, respectively) and the US (one-tenth and more than one-fifth of the total merchandise imports and exports, respectively) but tariff rates are quite low for the majority of commodities. In line with this structure of the foreign trade flows, data on tariff revenues of the government are not officially available. Therefore, tariff revenues and thus the tariff rates on imported commodities are assumed to be zero.

$$
P Q S_{c, t} Q S_{c, t}=P M_{c, t} Q M_{c, t}+P D_{c, t} Q D_{c, t}
$$

The value of total domestic demand by producer prices, $P Q S$, is equal to the values of imports and domestic sales of commodities. However, sales tax, carbon tax, and trade and transportation margins are paid by consumers and they are included in the purchaser price, $P Q D_{c}$, of commodity $c$.

$$
P Q D_{c, t}=\left(P Q S_{c, t}+\overline{P C A R}_{c, t} \operatorname{carcon}_{c} \alpha_{c}, t\right)\left(1+\operatorname{stax}_{c, t}\right)+\sum_{m} \operatorname{marg}_{-} d_{m, c} P T M_{m, t}
$$

Equation (85) shows the material balance of commodity supply and demand. The LHS is equal to total supply of composite commodity $c$ that is demanded for several purposes including trade and transportation margins.

$$
Q S_{c, t}=Q I N V_{c, t}+T O T P R C O N_{c, t}+Q I N T_{c, t}+C G_{c, t}+Q D T M_{c, t}
$$

The solution of $P X A C_{a, c, t}$, the price of commodity $c$ produced by activity $a$, comes from the solution of the problem defined by equations (64) and (65). Equation (86) is defined over the set of non-homogeneous commodities and of commodities produced in the base case, i.e. $S A M_{a, c}$ is non-zero. The price of activity commodities for homogeneous commodities produced in the base case is equal to their composite domestic commodity price, eq. (87), and is equal to zero for the other cases.

$$
\begin{gathered}
\left.P X A C_{a, c, t}\right|_{\left\{c p_{c} \text { and } c h n_{c}\right\}}=P X C_{c, t} Q X C_{c, t} \gamma_{a, c, t}^{q x c s} Q X A C_{a, c, t}^{\left(-\rho_{c, t}^{q x c s}-1\right)} \sum_{a}\left[\gamma_{a, c, t}^{q x c s} Q X A C_{a, c}^{-\rho_{c, t}^{q x c s}}\right]^{-1} \\
\left.P X A C_{a, c, t}\right|_{\left\{c h_{c}\right\}}=P X C_{c, t}
\end{gathered}
$$

\footnotetext{
13 The weight of the UK in total Irish international trade flows will be more important after full exit of the UK from the EU.
} 
There are two more prices: the price of composite commodity $c$ produced by domestic producers, $P X C_{c, t}$, and price of value added, $P V A_{a, t}$. These prices are solved by equations (67) and (22), respectively.

Since it is assumed that activities produce multiple products and eq. (65) is used in the multiple product determination problem, using it to solve for the price of output, $P X_{a, t}$, is not an option. Therefore, another variable namely $\gamma_{a, c, t}^{q x a c q x}$ is introduced as

$$
Q X A C_{a, c, t}=\gamma_{a, c, t}^{q x a c q x} Q X_{a, t}
$$

Note that this equation does NOT imply that multiple product determination is fixed share of total output in which case $\gamma_{a, c, t}^{q x a c q x}$ must be a parameter rather than a variable. Then, the output price is equal to

$$
P X_{a, t}=\sum_{c} \gamma_{a, c, t}^{q x a c q x} P X A C_{a, c, t}
$$

Price of (physical) investment is uniform across activities due to the fact that we can only observe the breakdown of total investment expenditures across commodities. To make this price activity-specific, we have to know the distribution of the activity's physical investment across commodities. In other words, we need to know the capital composition matrix of activity, which is not readily available in almost all countries.

$$
\mathrm{PPSI}_{t}=\prod_{c} P Q D_{c, t}^{\gamma_{c, t}^{\text {inorg }}}
$$

Equations (91) and (92) define consumer price index (CPI) and producer price index (PPI), respectively. The commodity weights of the CPI are equal to shares of commodities in total private consumption while the weights in the PPI are shares of commodities in total domestic production.

$$
\begin{gathered}
C P I_{t}=\sum_{c} w g t_{c, t}^{c p i} P Q D_{c, t} \\
P P I_{t}=\sum_{c} w g t_{c, t}^{p p i} P D_{c, t}
\end{gathered}
$$

$C P I_{1}$, the value of consumer price index in the first period, is chosen as the numéraire of the system, i.e. all prices are solved for relative to the $C P I_{1}$.

\section{Energy}

The flow of emissions through the economy is captured in $\mathrm{I} 3 \mathrm{E}$ by explicitly including energy/carbon commodities. The I3E model includes the following energy commodities: peat, coal, crude oil, gasoline, kerosene, fuel oil, liquid petroleum gas, diesel, electricity, natural gas, and other petroleum products. Crude oil and fuel oil are not subject to private consumption, i.e. households do not demand these energy commodities. The consumption of energy commodities regardless of the purpose causes $\mathrm{CO}_{2}$ emissions, 
with the exception of crude oil (which is transformed into other energy commodities) and electricity (which is generated using energy commodities). The parameter $\operatorname{carcon}_{c}$ takes a positive value for these energy commodities, which cause emissions and reflects the amount of emissions released per unit of the carbon commodity in Mt of $\mathrm{CO}_{2}$. For the other commodities defined in the model, the value of carcon $_{c}$ is equal to zero. Using this approach, the level of emissions needed to produce non-energy commodities can also be calculated. The level of emission for each energy commodity is calculated as

$$
\left.\operatorname{emis}_{c, t}\right|_{\left\{\operatorname{carcon}_{c}\right\}}=\operatorname{carcon}_{c} Q S_{c, t}
$$

The economy-wide total emissions is the summation of emissions per commodity

$$
\text { emis_tot }_{t}=\sum_{c} \text { emis }_{c, t}
$$

The economy-wide total emissions consists of emissions caused by activities in the production process (based on the intermediate input demand, eq. 26), households (based on the consumption demand, eq. 95), and government (based on the public demand, eq. 96).

$$
\begin{aligned}
\text { emis_hh }_{h h, t} & =\sum_{c} \operatorname{carcon}_{c} C D_{c, h h, t} \\
\text { emis_gov }_{t} & =\sum_{c} \operatorname{carcon}_{c} C G_{c, t}
\end{aligned}
$$

Equation (97) calculates the total residential emissions which includes private demand of energy commodities for residential heating purposes, i.e. the commodities under the nest of residential heating $(R H C)$ on Figure 1. Households' total emissions can be distinguished as residential and non-residential emissions in order to measure the effects of policy shocks on their behaviours regarding private consumption for different purposes.

$$
\text { emis_hhres }_{h h, t}=e m i s_{\_} h h_{h h, t}-\sum_{S P R V_{c}} \operatorname{carcon}_{c} C D_{c, h h, t}
$$

where $S P R V_{c}$ is a subset of energy commodities demanded for private transportation purposes and comprises TDie and GAL, under the nest of PRV on Figure 1.

\section{Economic Growth}

Economic growth has three sources: the growth of employment due to population growth, the growth in capital stock driven by investment, and the growth in total factor productivity, which is known as the Solow residual. This is the component of the economic growth that is not explained by growth in the factors of production.

As stated by Acemoglu (2009), if the technological progress is not of the Harrod-neutral form with 
any constant returns to scale (CRS) production function, per capita or aggregate variables cannot grow at a constant rate. This is referred to as a balanced growth path (BGP). The type of technological progress (capital augmented - Solow-neutral, labour augmented - Hicks-neutral) matters if the CRS production function is in a CES form in which the elasticity of substitution between capital and labour is not unity. If it is equal to 1 , which corresponds to a Cobb-Douglas type of production function, each technological progress produces identical results (Acemoglu, 2009, 71-2). Since the value added function is assumed to be in the form of CES, the technical change has to be labour-augmented.

It is assumed that the total population grows at a constant rate, $n_{t}$, and the technology, i.e. the productivity of the labour force, grows at a constant rate, $g_{t} \cdot{ }^{14}$ In mathematical terms,

$$
\begin{aligned}
P O P_{t+1} & =P O P_{t}\left(1+n_{t}\right) \\
\overline{B X}_{t+1} & =\overline{B X}_{t}\left(1+g_{t}\right)
\end{aligned}
$$

where $P O P_{t}$ is the total population at period $t$ and $\overline{B X}_{t}$ is the productivity level of the labour force at period $t$. In the case of labour-augmented technological growth, the growth of the productivity level of labour implies that the economy operates as if she has more labour (Acemoglu, 2009, 69).

The balanced growth path in a discrete time model requires that a variable should evolve as follows:

$$
x_{t+1}=x_{t}\left(1+n_{t}\right)\left(1+g_{t}\right)=x_{t}\left(1+n_{t}+g_{t}+n_{t} g_{t}\right)=x_{t}\left(1+g r w_{t}\right)
$$

where $g r w_{t}$ is the economic growth rate. In the current version, the values of $n$ and $g r w$ are retrieved from the medium-run estimates of the macroeconometric forecast model of the ESRI, namely COSMO (COre Structural MOdel for Ireland), Bergin et al. (2017). Accordingly, $n_{t}$ and $g r w_{t}$ are calibrated as $0.8 \%$ and $3.3 \%$. These population and economic growth rates imply $2.48 \%$ growth rate of the labour productivity.

\section{Saving-Investment}

Private, i.e. household, savings are determined endogenously as explained in the previous sections.

$$
\text { TOTPRSAV } V_{t}=\sum_{h h} S A V_{h h, t}
$$

Government savings, $G S A V_{t}$, are endogenously determined via the government budget constraint and the enterprise savings, $E S A V_{t}$, are a fixed fraction of the total net-of-corporate tax profits, eq. (43).

In the absence of financial markets, a CGE model is able to solve for one of the following: foreign trade balance/savings, nominal exchange rate, and price index/real exchange rate (Robinson, 1989, 921). Here, foreign savings, $\overline{F S A V_{t}}$, are assumed to be fixed, and the consumer price index's value in the first period is fixed, making it possible for the model to solve for the nominal exchange rate which equates to

\footnotetext{
14 In the current version, all growth rates are uniform across the model horizon. The time subscript is added to allow us to incorporate different growth rates through time.
} 
the foreign exchange movements. The value of total savings in the economy is

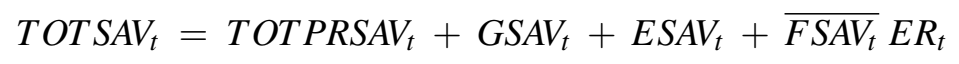

In the equilibrium, the sum of investment expenditures of activities, i.e. investment by destination, must be equal to the total demand of commodities for investment purposes, i.e. investment by origin.

$$
\begin{gathered}
\operatorname{TOTINV}_{t}=\sum_{a} I N V_{a, t} \\
P Q D_{c, t} Q I N V_{c, t}=\gamma_{c, t}^{\text {invorg }} \text { TOTINV }
\end{gathered}
$$

where $\gamma_{c, t}^{\text {invorg }}$ is the share of commodity $c$ in total volume of investment and $Q I N V_{c}$ is the volume of investment demand for commodity $c$.

\section{Equilibrium}

For the economy to be in equilibrium, all markets must be in equilibrium. In the relevant sections, the price and quantity equilibrium conditions were discussed. Here we discuss the foreign market equilibrium conditions.

The foreign market equilibrium, eq. (102), solves for the equilibrium exchange rate by equating foreign exchange supply and demand

$$
\sum_{c} P W E_{c, t} Q E_{c, t}+\sum_{h h} \overline{N F I}_{h h, t}+\overline{F S A V}_{t}=\sum_{c} P W M_{c, t} Q M_{c, t}+G F I N T_{t}+\frac{\sum_{a} C E T S_{a, t} 0.5}{E R_{t}}
$$

where the last item on the RHS of eq. (102) is the half of the cost of the ETS in foreign currency.

Up to this point, the number of endogenous variables and the number of equations are equal to each other, and there is no need to add an equation that shows investment-saving balance. If the system of equations is defined correctly, i.e. if there is no error in the model, investment and savings will be equal

to each other by definition. However, rather than dropping this equation, it is conventionally associated with a slack variable, namely Walras. If there is no error in the model, WALRAS $=0$ should hold for every period $t$ and experiment.

$$
\operatorname{TOTSAV}_{t}=T O T I N V_{t}+W A L R A S_{t}
$$




\section{Appendix A Lists of Activities and Commodities}

Table A.1: Activities

\begin{tabular}{|c|c|c|c|c|c|c|}
\hline Abbreviation & Name & NACE Codes & $\sigma_{B E N}$ & $\sigma_{F U E}$ & $\sigma_{B H}$ & $\sigma_{\text {OTE }}$ \\
\hline ACC & Accommodation and Hotel Services & $55-56,79$ & 1.5 & 0 & 0 & \\
\hline AGR & Agriculture & $1-3$ & 1.5 & 0 & 0 & \\
\hline ATS & Air Transportation & 51 & 0 & 1.3 & 1.3 & \\
\hline BFM & Basic Metal Manufacturing & $24-25$ & 1.5 & 1.3 & 1.3 & \\
\hline BPP & Basic Pharmaceutical Products & 21 & 1.5 & 0 & 0 & \\
\hline CHE & Chemical Products & 20 & 1.5 & 1.5 & 1.5 & \\
\hline $\mathrm{CON}$ & Construction & $41-43$ & 1.5 & 0 & 1.5 & \\
\hline EDU & Education Sector & 85 & 1.5 & 1.3 & 1.5 & \\
\hline FBT & Food, Beverage and Tobacco & $10-12$ & 1.5 & 1.5 & 1.5 & \\
\hline FSR & Financial Services & $64-66,77$ & 1.5 & 0 & 0 & \\
\hline HHS & Health Sector & $86-88$ & 1.5 & 1.3 & 1.3 & \\
\hline HTP & High-Technology Products & $26-28$ & 1.5 & 1.5 & 1.5 & \\
\hline LTS & Land Transportation & 49 & 1.3 & 0 & 1.3 & \\
\hline NGS & Natural Gas Supply & & 0 & 1.3 & 0 & \\
\hline OIN & Other Industrial Products & $17,18,33$ & 1.5 & 1.5 & 1.3 & \\
\hline $\mathrm{OMN}$ & Other Mining Products & & 1.5 & 1.3 & 1.5 & \\
\hline ONM & Other Non-metallic Products & 23 & 1.5 & 1.3 & 1.5 & \\
\hline OTM & Other Manufacturing & $31-32$ & 1.3 & 1.5 & 0 & \\
\hline PEA & Peat & & 1.5 & 1.3 & 1.5 & \\
\hline PET & Petroleum & & 0 & 0 & 0 & \\
\hline PUB & Public Sector & 84 & 1.5 & 1.3 & 1.5 & \\
\hline RES & Real Estate Services & 68 & 1.5 & 0 & 0 & \\
\hline RUP & Rubber and Plastic Products & 22 & 1.5 & 1.5 & 1.3 & \\
\hline SER & Other Services & remaining* & 1.5 & 0 & 0 & \\
\hline TEL & Telecommunication Services & 61 & 1.5 & 0 & 0 & \\
\hline TEX & Textile & $13-15$ & 1.5 & 1.5 & 1.3 & \\
\hline TRD & Trade & $45-47$ & 1.5 & 1.5 & 0 & \\
\hline TRE & Transportation Equipment & $29-30$ & 1.5 & 1.5 & 0 & \\
\hline WAT & Water and Sewerage & $36,37-39$ & 1.5 & 1.5 & 1.3 & \\
\hline WTS & Water Transportation & 50 & 0 & 0 & 0 & \\
\hline WWP & Wood and Wood Products & 16 & 1.5 & 1.3 & 0 & \\
\hline ELC & Electricity & & 1.2 & & & 1.5 \\
\hline
\end{tabular}

*: It excludes NACE codes 5-9 (Mining, Quarrying and Extraction), 19 (Petroleum Products), and 35

(Electricity and Gas Supply).

Note: The activities without NACE codes are further disaggregated sectors. 
Table A.2: Commodities

\begin{tabular}{|c|c|c|c|}
\hline AGR & Agriculture & BFM & Basic metal manufacturing \\
\hline PEA & Peat & HTP & High-technology products \\
\hline $\mathrm{COA}$ & Coal & TRE & Transportation equipment \\
\hline $\mathrm{CRO}^{*}$ & Crude oil & ELC & Electricity \\
\hline $\mathrm{OMN}^{*}$ & Other mining products & NGS & Natural gas supply \\
\hline FBT & Food, beverage and tobacco & WAT & Water and sewerage \\
\hline TEX & Textile & $\mathrm{CON}$ & Construction \\
\hline WWP & Wood and wood products & TRD & Trade \\
\hline OIN & Other industrial products & LTS & Land transportation \\
\hline GAL & Gasoline & WTS & Water transportation \\
\hline KRS & Kerosene & ATS & Air transportation \\
\hline FUO* & Fuel oil & $\mathrm{ACC}$ & Accommodation and hotel services \\
\hline LPG & Liquid petroleum gas & TEL & Telecommunication services \\
\hline DIE & Diesel & FSR & Financial services \\
\hline OPP & Other petroleum products & RES & Real estate services \\
\hline OTM & Other manufacturing & PUB & Public services \\
\hline $\mathrm{CHE}$ & Chemicals and chemical products & EDU & Education sector \\
\hline BPP & Basic pharmaceutical products & HHS & Health sector \\
\hline RUP & Rubber and plastic products & SER & Other services \\
\hline ONM & Other non-metallic products & & \\
\hline
\end{tabular}

*: Not subject to private consumption. 


\section{Appendix B List of Endogenous Variables}

\begin{tabular}{|c|c|}
\hline Name & Description \\
\hline$A D J_{a, t}$ & Adjustment cost \\
\hline AtoT $_{a, t}$ & Allowance to total ETS emissions ratio \\
\hline $\operatorname{CCIN}_{c, a, t}$ & Intermediate demand of activity-specific composite commodity $c$ \\
\hline$C C Q S_{c, h h, t}$ & Consumption of household-specific composite commodity $c$ \\
\hline$C D_{c, h h, t}$ & Consumption demand of households by commodity $c$ \\
\hline$C G_{c, t}$ & Consumption demand of government by commodity $c$ \\
\hline $\operatorname{CINC}_{h h, t}$ & Capital (dividend) income \\
\hline$C L D_{a, t}$ & Composite labour demand \\
\hline $\operatorname{corptax}_{t}$ & Corporate tax rate \\
\hline CORPTAXS & Corporate tax payments \\
\hline $\operatorname{CostETS}_{a, t}$ & Cost of ETS \\
\hline$C P I_{t}$ & Consumer price index \\
\hline$C T A X S_{c, t}$ & Value of carbon tax revenues \\
\hline$C T X A D J_{a, c, t}$ & Carbon tax exemption adjuster for activities \\
\hline$C W_{a, t}$ & Composite wage \\
\hline$D I S D I V_{t}$ & Total distributed dividends \\
\hline$D I V_{a, t}$ & Sectoral dividends \\
\hline emis $s_{c, t}$ & Commodity emissions \\
\hline emis_act ${ }_{a, t}$ & Activity emissions \\
\hline emis_ETS $S_{a, t}$ & ETS emissions \\
\hline emis_govt & Government emissions \\
\hline emis_hh $h_{h h, t}$ & Household emissions \\
\hline emis_OETS $S_{a, t}$ & Other ETS (process) emissions \\
\hline emis_res ${ }_{h h, t}$ & Residential emissions of households \\
\hline emis_tot $t_{t}$ & Economy-wide emissions \\
\hline$E R_{t}$ & Level of exchange rate \\
\hline$E S A V_{t}$ & Savings of enterprises \\
\hline$E T S A D J_{a, t}$ & ETS cost adjuster for activities \\
\hline$E X P T A X S_{c, t}$ & Export tax \\
\hline$G D P_{t}$ & Gross domestic product \\
\hline$G F D S_{t}$ & Government foreign debt stock \\
\hline$G F I N T_{t}$ & Interest payments of the government to RoW \\
\hline GOVCON $_{t}$ & Total government consumption expenditures \\
\hline$G O V R E V_{t}$ & Government revenues \\
\hline
\end{tabular}




\begin{tabular}{|c|c|}
\hline$G S A V_{t}$ & Government savings \\
\hline$I N C_{h h, t}$ & Disposable income \\
\hline$I N T_{c, a, t}$ & Intermediate input demand of activity $a$ by commodity $c$ \\
\hline$I N V_{a, t}$ & Investment by destination \\
\hline$K_{a, t}$ & Sectoral capital stock \\
\hline$K S U P_{t}$ & Total capital stock \\
\hline$L D_{a, l, t}$ & Labour demand for labour $l$ by activity $a$ \\
\hline$L S U P_{l, t}$ & Labour supply \\
\hline$N M I G_{t}$ & Total net migration \\
\hline$N M I G L_{l, t}$ & Net migration by type of labour \\
\hline$N M T T R_{h h, t}$ & Non-means-tested transfer receipt of household $h h$ \\
\hline$N W I N C_{t}$ & Per capita net-of-tax wage income in Ireland \\
\hline $\operatorname{PCIN}_{c, a, t}$ & Price of activity-specific composite commodity $c$ \\
\hline$P C Q S_{c, h h, t}$ & Price of household-specific composite commodity $c$ \\
\hline$P D_{c, t}$ & Consumer price of domestic supply of commodity $c$ \\
\hline$P E_{c, t}$ & Export price of commodity c (including export tax) in domestic currency \\
\hline$P E N_{h h, t}$ & Pension income of households \\
\hline$P M_{c, t}$ & Price of import commodity c including import tax) in domestic currency \\
\hline$P P I_{t}$ & Producer (domestic) price index \\
\hline $\mathrm{PPSI}_{t}$ & Price of investment \\
\hline$P Q D_{c, t}$ & Purchaser price of composite commodity $c$ \\
\hline$P Q S_{c, t}$ & Supply price of composite commodity $c$ \\
\hline $\operatorname{prodtax}_{a, t}$ & Production tax rate \\
\hline PRODTAXS $S_{a, t}$ & Taxes on production payments by activity $a$ \\
\hline$P S I_{a, t}$ & Physical investment \\
\hline$P T A D J_{t}$ & Uniform production tax rate adjuster \\
\hline$P T A D J P_{t}$ & Partial production tax rate adjuster \\
\hline$P T M_{m, t}$ & Price of margin \\
\hline$P V A_{a, t}$ & Price of sectoral value added \\
\hline$P X_{a, t}$ & Price of sectoral output \\
\hline$P X A C_{a, c, t}$ & Price of commodity $c$ produced by activity $a$ \\
\hline$P X C_{c, t}$ & Price of composite domestic commodity $c$ \\
\hline$q_{a, t}$ & Tobin $q$ \\
\hline$Q D_{c, t}$ & Total domestic supply of commodity $c$ \\
\hline$Q D T M_{c, t}$ & Total demand of margin \\
\hline$Q E_{c, t}$ & Total export of commodity $c$ \\
\hline$Q I N T_{c, t}$ & Total intermediate input demand of good \\
\hline$Q I N V_{c, t}$ & Investment demand of good \\
\hline
\end{tabular}




\begin{tabular}{|c|c|}
\hline$Q M_{c, t}$ & Total import demand of commodity $c$ \\
\hline$Q S_{c, t}$ & Composite supply of commodity $c$ \\
\hline$Q S T M_{m, t}$ & Total supply of margin \\
\hline$Q X_{a, t}$ & Sectoral output \\
\hline$Q X A C_{a, c, t}$ & Production of commodity $c$ by activity $a$ \\
\hline$Q X C_{c, t}$ & Total production of commodity $c$ by domestic producers \\
\hline$R C I_{h h, t}$ & Revenue recycling income of hh \\
\hline$R I N C_{h h, t}$ & Real disposable income \\
\hline$S A L T A X_{c, t}$ & Value of sales tax revenues \\
\hline$S A V_{h h, t}$ & Savings \\
\hline shr_qxacqx $x_{a, c}$ & Share of commodity $c$ in production of activity $a$ \\
\hline$S T A D J_{t}$ & Uniform sales tax rate adjuster \\
\hline$S T A D J P_{t}$ & Partial sales tax rate adjuster \\
\hline $\operatorname{stax}_{c, t}$ & Sales tax rate \\
\hline$T_{A R I F} S_{c, t}$ & Sectoral tariff revenues \\
\hline TOTINV & Total investment (expenditure) \\
\hline TOTPRCON ${ }_{c, t}$ & Total private consumption by good \\
\hline TOTPRSAV ${ }_{t}$ & Total private savings \\
\hline$T O T S A V_{t}$ & Total savings \\
\hline TPRODTAX $S_{t}$ & Total production tax collection \\
\hline$T R_{h h, t}$ & Transfer receipt \\
\hline TSALTAX & Total sales tax collection \\
\hline$T W T A X S_{t}$ & Total wage tax collection \\
\hline$U N_{l, t}$ & Number of unemployed by type of labour \\
\hline$U N R_{l, t}$ & Unemployment rate by type of labour \\
\hline$V A_{a, t}$ & Sectoral value added \\
\hline$W_{l, t}$ & Wage rate \\
\hline$W$ mean $_{t}$ & Average wage \\
\hline$W A L R A S_{t}$ & Slack variable for walras's law \\
\hline$w g t_{-} c p i_{c, t}$ & Share of commodity $c$ in total private consumption $=$ weights in $\mathrm{CPI}$ \\
\hline$w g t_{-} p p i_{c, t}$ & Share of commodity $c$ in total domestic production $=$ weights in PPI \\
\hline$W I N C_{h h, t}$ & Wage income \\
\hline$W K_{a, t}$ & Price of capital \\
\hline$W T A D J_{t}$ & Uniform wage tax rate adjuster \\
\hline$W T A D J P_{t}$ & Partial wage tax rate adjuster \\
\hline$w_{t a x} h, t$ & Wage tax rate (including SSI premiums) \\
\hline$W T A X S_{h h, t}$ & Wage income tax payments \\
\hline
\end{tabular}




\section{Appendix C List of Exogenous Variables and Parameters}

\begin{tabular}{ll} 
Name & Description \\
\hline$\overline{\text { allowance }}_{a, t}$ & ETS allowance \\
$\overline{\text { allowance_oth }}_{a, t}$ & Other ETS (process) emissions \\
$\overline{B X}_{t}$ & Level of technical efficiency \\
$\overline{F S A V}_{t}$ & Foreign savings \\
$\overline{G O V C O N A}_{t}$ & Autonomous government consumption expenditures \\
$\overline{G T R E N T}_{t}$ & Transfers from government to enterprises \\
$\overline{G T R H H}_{t}$ & Transfers from government to households \\
$\overline{N F I}_{h h, t}$ & Net factor income from abroad \\
$\overline{N F W I N C}_{t}$ & Per capita total net-of-tax wage income abroad \\
$\overline{P C A R}_{t}$ & Carbon price \\
$\overline{P E T S}_{t}$ & Price of ETS permit \\
$\overline{T O T P E N}_{t}$ & Total pension transfer of government to households \\
$\overline{T P O P}_{t}$ & Total population \\
$W F D I S T_{l, a, t}$ & Sectoral proportion for factor prices \\
\hline
\end{tabular}

\section{Parameters}

$\phi_{a, t}$

$\sigma_{c, t}^{a r m}$

$\rho_{c, t}^{a r m}$

$\gamma_{c, t}^{a r m}$

$\lambda_{c, t}^{a r m}$

$P T 01_{a, t}$

$S T 01_{c, t}$

$W T 01_{h h, t}$

carcon $_{c, t}$

$\alpha_{c, t}$

$\mathrm{RCHH}_{t}$

$R C C T_{t}$

$R C G C_{t}$

$R C P T_{t}$

$R C S T_{t}$

$R C W T_{t}$
Adjustment parameter of investment

Armingtan elasticity

Armington exponent

Armington share parameter

Armington shift parameter

Binary production tax rate adjuster

Binary sales tax rate adjuster

Binary wage tax rate adjuster

Carbon content of commodity $c$

Carbon tax leakage parameter

Carbon tax revenue recycling (CTRR) switching parameter for transfer to households

CTRR switching parameter for corporate tax rate reduction

CTRR switching parameter for government consumption

CTRR switching parameter for production tax rate reduction

CTRR switching parameter for sales tax rate reduction

CTRR switching parameter for wage tax rate reduction 


\begin{tabular}{|c|c|}
\hline$\sigma_{c, t}^{q x c s}$ & CES (supply) of QXC elasticity \\
\hline$\rho_{c, t}^{q x c s}$ & CES (supply) of QXC exponent \\
\hline$\gamma_{a, c, t}^{q x c s}$ & CES (supply) of QXC share parameter \\
\hline$\lambda_{c, t}^{q x c s}$ & CES (supply) of QXC shift parameter \\
\hline$\sigma_{a, t}^{b h}$ & CES of business heating $(\mathrm{BH})$ elasticity \\
\hline$\rho_{a, t}^{b h}$ & CES of business heating $(\mathrm{BH})$ exponent \\
\hline$\gamma_{c, a, t}^{b h}$ & CES of business heating $(\mathrm{BH})$ share parameter \\
\hline$\sigma_{a, t}^{c l d}$ & CES of CLD elasticity \\
\hline$\rho_{a, t}^{c l d}$ & CES of CLD exponent \\
\hline$\gamma_{a, l, t}^{c l d}$ & CES of CLD share parameter \\
\hline$\sigma_{a, t}^{v a}$ & CES of VA elasticity \\
\hline$\rho_{a, t}^{v a}$ & CES of VA exponent \\
\hline$\gamma_{a, t}^{c v a}$ & CES of VA share parameter \\
\hline$\lambda_{a, t}^{v a}$ & CES of VA shift parameter \\
\hline$\sigma_{c, t}^{q x c d}$ & CET (demand) of QXC elasticity \\
\hline$\rho_{c, t}^{q x c d}$ & CET (demand) of QXC exponent \\
\hline$\gamma_{c, t}^{q x c d}$ & CET (demand) of QXC share parameter \\
\hline$\lambda_{c, t}^{q x d}$ & CET (demand) of QXC shift parameter \\
\hline$\sigma_{a, t}^{q x a c}$ & CET of QX elasticity of production \\
\hline$\rho_{a, t}^{q x a c}$ & CET of QX exponent \\
\hline$\gamma_{a, c, t}^{q x a c}$ & CET of QX share parameter \\
\hline$\lambda_{a, t}^{q x a c}$ & CET of QX shift parameter \\
\hline$\zeta_{0, t}$ & Constant coefficient in net migration function \\
\hline$\omega_{0, l, t}$ & Constant coefficient in wage equation \\
\hline$\delta_{a, t}$ & Depreciation rate \\
\hline$g r w_{t}$ & Economic growth rate \\
\hline$\gamma_{h h, t}^{s a v}$ & Enterprises saving rate \\
\hline ETSto $_{a, t}$ & ETS emissions in total emissions \\
\hline $\operatorname{exptax}_{c, t}$ & Export tax rate on exported commodity $c$ \\
\hline$r f_{t}$ & Foreign interest rate \\
\hline$\theta_{h h, t}$ & Intertemporal elasticity of substitution \\
\hline$\tau_{l, t}$ & Labour force participation rate of $l$ \\
\hline $\operatorname{marg}_{m, c, t}^{d}$ & Margin demand share in total composite commodity $c$ \\
\hline $\operatorname{marg}_{c, m, t}^{s}$ & Margin supply share in total supply \\
\hline$M P S_{t}$ & Marginal propensity to spend over GDP \\
\hline allow $w_{a, t}^{o t h}$ & Other ETS allowances per output for ONM and ATS \\
\hline emis ${ }_{a, t}^{\text {oth }}$ & Other ETS emissions per output for ONM and ATS \\
\hline$n_{t}$ & Population growth rate \\
\hline
\end{tabular}




$\begin{array}{ll}\gamma_{c, t}^{g c} & \text { Share of commodity } c \text { in total government demand } \\ \gamma_{h h, t}^{\text {chnc }} & \text { Share of household } h h \text { in capital income } \\ \gamma_{h h, t}^{\text {gtrhh }} & \text { Share of household } h h \text { in government transfers } \\ \gamma_{h h, t}^{\text {penhh }} & \text { Share of household } h h \text { in pensions } \\ \gamma_{h h, t}^{\text {rh }} & \text { Share of household } h h \text { in recycling income } \\ \gamma_{l, h h, t}^{\text {wage }} & \text { Share of household } h h \text { in wage income } \\ \gamma_{a, t}^{\text {indes }} & \text { Share of investment demand (=inv. by destination) in gross profits (positive for NDM) } \\ \gamma_{c, t}^{\text {invorg }} & \text { Share of investment demand by commodity } c \text { (=inv. by origin) in total investment } \\ \mu_{l, t} & \text { Share of labour } l \text { in total net migration } \\ \zeta_{1, t} & \text { Slope coefficient in net migration function } \\ \omega_{1, l, t} & \text { Slope coefficient in wage equation } \\ t a r i f f_{c, t} & \text { Tariff rate on imported commodity } \\ g_{t} & \text { Technology growth rate } \\ \rho_{h h, t} & \text { Time-preference rate } \\ P W E_{c, t} & \text { World price of exported goods } \\ P W M_{c, t} & \text { World price of imported goods }\end{array}$

\section{Appendix D How do activities internalise the cost of the ETS and the car- bon tax exemptions?}

The value of production is given by eq. (22). By definition, the total cost of the intermediate input demand is equal to the total cost of the composite intermediate inputs (VA, BEN, OTI) which, in turn, is the sum of the cost of intermediate inputs (VA is equal to the cost of the factors of production, OTI is equal to the cost of the non-energy intermediate inputs, etc.).

The carbon tax paid by activity $a$ for commodity $c$ is equal to the carbon tax burden embedded in the purchaser price of commodity $c$ multiplied by the amount of intermediate demand for it. From eq. (84), the total value of the carbon tax payment of activity $a$ is equal to

$$
\sum_{c} \overline{P C A R}_{c, t} \operatorname{carcon}_{c} \alpha_{c}, t\left(1+\operatorname{stax}_{c, t}\right) I N T_{c, a, t}
$$

An activity subject to the ETS is exempted from paying the carbon tax based on the fraction of its emissions covered by the ETS. In order to take this into account, we need to multiply eq. (D.1) by 
$E T S t o E_{a, t}$. Plugging this term and equations (49) and (30) into eq. (22) results in

$$
\begin{aligned}
P X_{a, t} Q X_{a, t} & =P V A_{a, t} V A_{a, t}+\operatorname{prodtax}_{a, t} P X_{a, t} Q X_{a, t}+\sum_{c} P Q D_{c, t} I N T_{c, a, t} \\
+\overline{P E T S_{t}} & \left(\text { emis_ETS }_{a, t}+\text { emis_oETS }_{a, t}-{\overline{\text { allowance }_{a, t}}}_{-\overline{\text { allowance_oth }}_{a, t}}\right) \\
& -\sum_{c} \overline{P C A R}_{c, t} \text { carcon }_{c} \alpha_{c}, t\left(1+\operatorname{stax}_{c, t}\right) I N T_{c, a, t} \text { ETStoE }_{a, t}
\end{aligned}
$$

By further plugging equations (26-29)

$$
\begin{gathered}
\left(1-\operatorname{prodtax}_{a, t}\right) P X_{a, t} Q X_{a, t}=P V A_{a, t} V A_{a, t}+\sum_{c} P Q D_{c, t} I N T_{c, a, t} \\
+\overline{P E T S_{t}} \sum_{c}\left[\operatorname{carcon}_{c} I N T_{c, a, t} \text { ETStoE }_{a, t}\left(1-\text { Ato }_{a, t}\right)\right] \\
\quad+\overline{\text { PETS S }} \text { QX }_{a, t} \text { emis_oth }_{a, t}-\text { allow_oth }_{a, t} Q X_{a, t} \\
-\sum_{c} \overline{P C A R}_{c, t} \text { carcon }_{c} \alpha_{c}, t\left(1+\text { stax }_{c, t}\right) I N T_{c, a, t} \text { ETStoE }_{a, t}
\end{gathered}
$$

The second line of eq. (D.3) is the cost of ETS concerning the emissions of an activity based on its energy consumption, and the third line is the cost of ETS regarding the process emissions based on the level of output. The fourth line deducts the carbon tax exemptions.

Rearranging yields,

$$
\begin{gathered}
\left(1-\operatorname{prodtax}_{a, t}\right) P X_{a, t} Q X_{a, t}=P V A_{a, t} V A_{a, t}+\overline{P E T S_{t}}\left(\text { emis_oth }_{a, t}-\text { allow_oth }_{a, t}\right) Q X_{a, t} \\
+\sum_{c}\left(P Q D_{c, t}+\operatorname{ETSADJ}_{c, a, t}-\operatorname{CTXADJ}_{c, a, t}\right) I N T_{c, a, t}
\end{gathered}
$$

where $E T S A D J_{c, a, t}$ and $C T X A D J_{c, a, t}$ are given by equations (24) and (25), respectively. The existence of the ETS hence affects the unit cost of the intermediate input.

\section{Appendix E Updates Between the Model Versions}

\section{E.1 Major differences}

- The SAM and thus the system of equation has been updated as follows.

1. In the previous version, the wage income tax was paid by the labour accounts. In the new version, the HBS shares of households in tax payments are calibrated, and the total wage income tax of the government is distributed across households based on these shares, i.e. the wage income tax is paid by households. The system of equations has been updated accordingly.

2. In the former version, the total value of the net factor income from abroad was distributed across households based on their shares in capital income retrieved from the HBS, and household savings were residual. In the new version, the HBS shares of households in total private 
savings are retrieved and used to disaggregate total private savings across households, and the net factor income is residual. This change to the SAM does not lead to any alterations in the system of equations.

- In order to analyse the impacts of the COVID-19 crisis, a non-means-tested government transfer item has been introduced into the system of equations. Its value is set to zero along any scenario path unless otherwise stated.

- The shift parameters of the components of composite consumption were not defined as they were equal to 1 . In this version, they have been defined, their values have been set to 1 , and the calibration and the system of equation sections have been updated accordingly. In addition to the share parameters, they provide a second tool to change the composition of consumption across its components.

\section{E.2 Extensions}

- The EU-ETS has been updated by introducing the carbon tax exemptions of the sectors covered by the EU-ETS legislation. In this respect, as explained in Appendix D, each firm takes into account both the cost of the ETS and the carbon tax exemptions in its cost minimisation problem.

- The labour market structure has been updated. In the previous version, for the fixed level of labour supply, the labour market equilibrium was solving for the equilibrium wage rate. The current version, on the other hand, includes involuntary unemployment and international migration. In this version, the net migration inflows to Ireland are a function of the per employee net-of-tax wage income differential between Ireland and the rest of the world. There are three wage equations that relate the log of real wage rate and the log of unemployment rate for each type of labour. 


\section{References}

Acemoglu, D. (2009). Introduction to Modern Economic Growth. Princeton University Press.

Bergin, A., Conefrey, T., FitzGerald, J., Kearney, I., \& Žnuderl, N. (2013). The HERMES-13 Macroeconomic Model of the Irish Economy (Working Paper No. 460). Economic and Social Research Institute (ESRI). https://www.esri.ie/publications/the-hermes-13-macroeconomic-model -of-the-irish-economy.

Bergin, A., Conroy, N., Rodriguez, A. G., Holland, D., McInerney, N., Morgenroth, E. L., \& Smith, D. (2017). COSMO: A new COre Structural MOdel for Ireland (Tech. Rep.). ESRI Working Paper.

Environmental Protection Agency (EPA). (2018). Who needs a Permit? https://www.epa.ie/ climate/emissionstradingoverview/etscheme/etsi/.

EU-ETS. (2018). EU Emissions Trading System (EU ETS). https://ec.europa.eu/clima/ policies/ets_en.

Hayashi, F. (1982). Tobin's Marginal $q$ and Average $q$ : A Neoclassical Interpretation. Econometrica, 50(1), 213-224.

Kearney, I. (1998). Is There A Stable Migration Equation For Ireland? (Working Paper No. 97). Economic and Social Research Institute (ESRI). https://www.esri.ie/publications/is-there-a -stable-migration-equation-for-ireland.

Robinson, S. (1989). Multisectoral Models. In H. Chenery \& T. Srinivasan (Eds.), Handbook of development economics (Vol. 2, p. 885-947). Elsevier.

Sustainable Energy Authority of Ireland. (2013). Energy in the Residential Sector (Tech. Rep.). https://www.seai.ie/resources/publications/Energy-in-the-Residential-Sector -2013.pdf. 
Whitaker Square,

Sir John Rogerson's Quay, Dublin 2

Telephone +35318632000

Email admin@esri.ie

Web www.esri.ie

Twitter @ESRIDublin

ISBN 978-0-7070-0527-0 